\title{
DESENVOLVIMENTO E AVALIAÇÃO DE TUBOS VENTURI PARA MEDIÇÃO DE VAZÃO
}

\section{RUBÉN ALCIDES FRANCO IBARS}

\author{
Dissertação apresentada à Escola Superior de \\ agricultura "Luiz de Queiroz", Universidade de São \\ Paulo, para obtenção do título de Mestre em \\ Agronomia, Área de concentração: Irrigação e \\ Drenagem.
}

\author{
PIR A C I C A B A \\ Estado de São Paulo - Brasil \\ Janeiro - 2004
}




\title{
DESENVOLVIMENTO E AVALIAÇÃO DE TUBOS VENTURI PARA MEDIÇÃO DE VAZÃO
}

\section{RUBÉN ALCIDES FRANCO IBARS}

\author{
Engenheiro Agrônomo
}

Orientador: Prof. Dr. TARLEI ARRIEL BOTREL

\author{
Dissertação apresentada à Escola Superior de \\ agricultura "Luiz de Queiroz", Universidade de São \\ Paulo, para obtenção do título de Mestre em \\ Agronomia, Área de concentração: Irrigação e \\ Drenagem. \\ PIRACICABA \\ Estado de São Paulo - Brasil \\ Janeiro - 2004
}




\section{Dados Internacionais de Catalogação na Publicação (CIP)} DIVISÃO DE BIBLIOTECA E DOCUMENTAÇÃO - ESALQ/USP

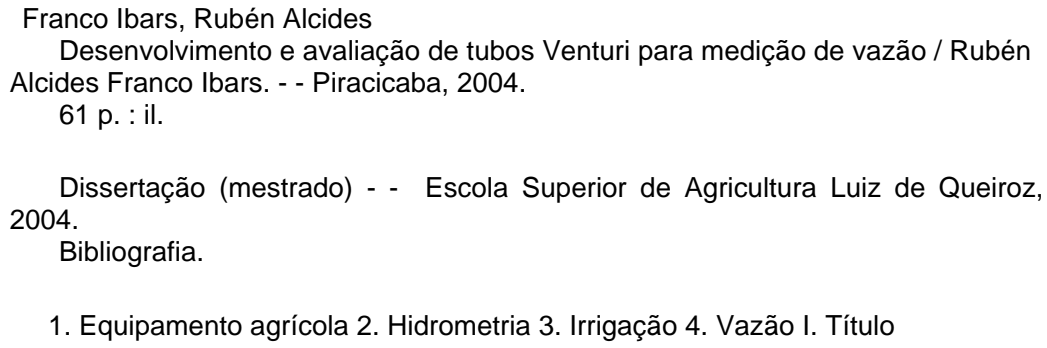

1. Equipamento agrícola 2. Hidrometria 3. Irrigação 4. Vazão I. Título

CDD 631.7

\section{"Permitida a cópia total ou parcial deste documento, desde que citada a fonte - O autor"}


"In memoriam" aos meus pais, Clinio Franco e Rubi Ibars, pela vida e ensinamentos.

\section{OFEREÇO}




\section{AGRADECIMENTOS}

A Deus pela força.

À Escola Superior de Agricultura "Luiz de Queiroz" (ESALQ/USP), através do Departamento de Engenharia Rural, pela acolhida e efetivo apoio concedidos.

À Coordenadoria de Aperfeiçoamento de Pessoal de Nível Superior (CAPES), pela concessão de bolsa de estudos.

À Faculdade de Ciências Agrárias/UNA, pelo afastamento concedido durante este tempo.

Ao prof. Dr. Tarlei Arriel Botrel, pelos ensinamentos oferecidos, pela orientação e amizade no decorrer do curso.

Ao amigo Nicolás Zárate, pelo apoio e incentivo para começar o mestrado.

Aos funcionários do DER-ESALQ/USP, em especial Davilmar, César e Hélio, Antônio e Osvaldo, pelo apoio e atenção.

Aos professores e colegas do Curso de Pós-Graduação em Irrigação e Drenagem, pela contribuição em minha formação científica e humana.

Ao Prof. Sérgio Nascimento Duarte pelas sugestões e colaborações.

Aos colegas Miguel Toledo, Rodrigo, Denis e Eliezer, pela orientação na área de eletrônica e programação.

Aos colegas José Bonnin, Miguel Ferreira, René, Saulo, Marcelo, Flávia, Vinicius, José Alves, Tonny, pelo companheirismo e amizade.

Enfim a todos aqueles que, direta ou indiretamente, tenham contribuído para o êxito de este trabalho. 


\section{SUMÁRIO}

Página

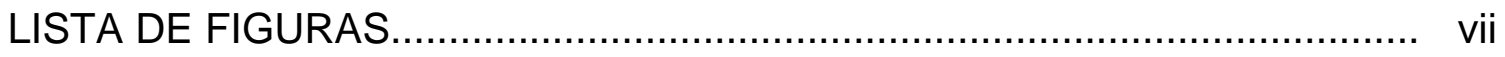

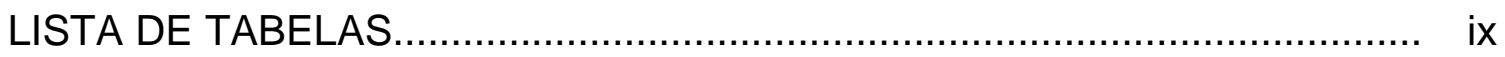

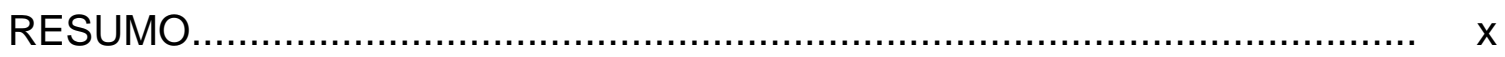

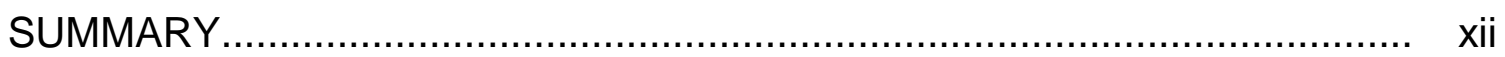

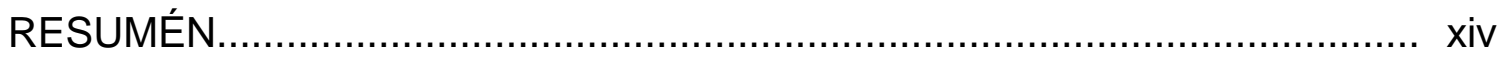

1 INTRODUÇÃO

2 REVISÃO DE LITERATURA................................................................. 3

2.1 Medição de água na agricultura......................................................... 3

2.2 Tipos de medidores de vazão......................................................... 4

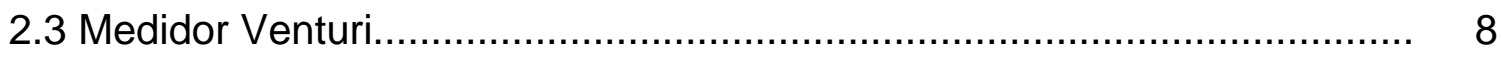

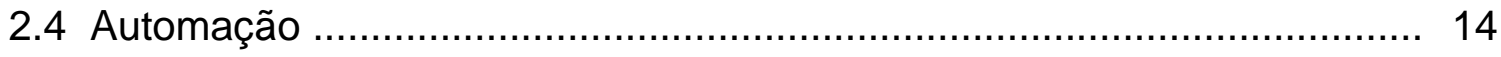

3 MATERIAL E MÉTODOS............................................................ 18

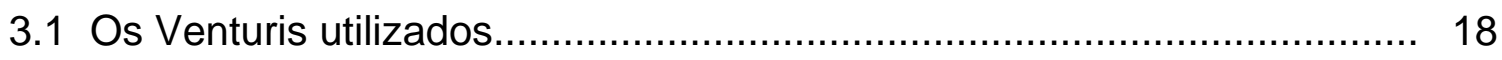

3.2 Circuito eletro-eletrônico.................................................................... 23

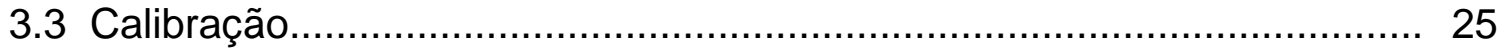

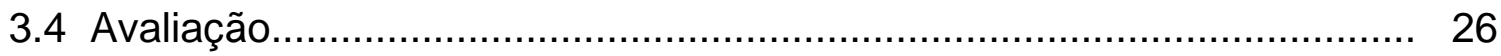

4 RESULTADOS E DISCUSSÃO .......................................................... 30

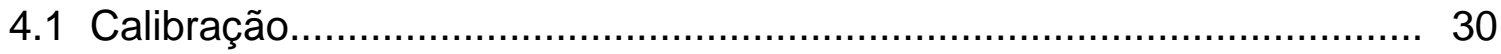

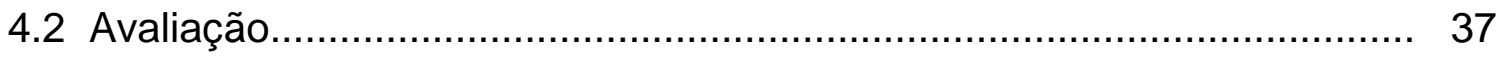

4.3 Coeficiente de descarga .............................................................. 42

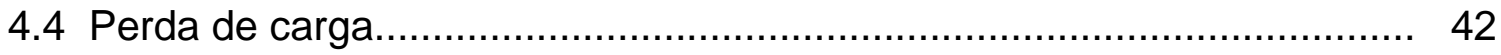

4.5 Lista de materiais e relação de preços.................................................... 44 


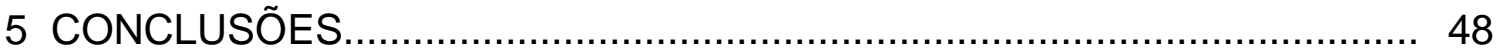

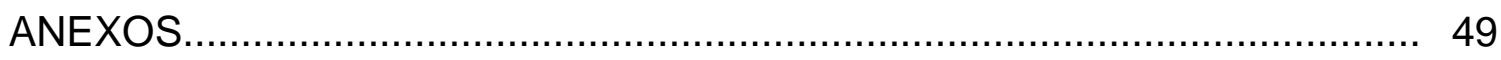

REFERÊNCIAS BIBLIOGRÁFICAS........................................................ 55 


\section{LISTA DE FIGURAS}

Página

1 Medidores de vazão por diferencial de pressão, orifício(a), bocal(b), Venturi(c).

2 Perda de carga em porcentagem do diferencial de pressão vs. relação entre o diâmetro da garganta e a tubulação principal......................... 7

3 Composição típica de um medidor Venturi.................................... 12

4 Materiais utilizados na construção dos tubos Venturi: moldes de PVC (a), tubulação de PVC (b), manta de fibra de vidro (c), sistema de extração das molduras (d), tomadas de pressão (e), Venturi Terminado e com os adaptadores roscáveis (f) ........................................ 19

5 Dimensões do Venturi 1 (DN 50) ......................................... 21

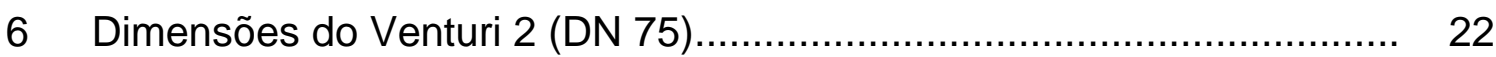

7 Vista geral do medidor Venturi com os componentes eletrônicos (a), transdutor de pressão (b), microcontrolador Basic Step (c), display

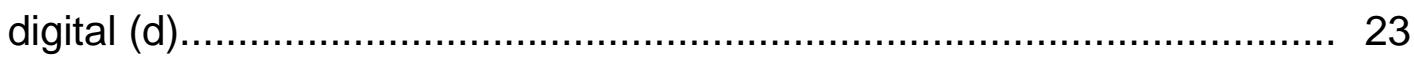

8 Esquema da placa de fenolite utilizada para montagem dos componentes eletro-eletrônicos............................................ 25

9 Sensor de vazão GF SIGNET 2536 (a); transmissor de vazão GF SIGNET 8550 (b); montagem típica dos mesmos (c)....................... 28

10 Dados de vazão vs. sinal digital para o Venturi 1 (a) e Venturi 2 (b)....... 31

11 Valores de vazão vs. raiz quadrada do sinal digital para os Venturi 1 (a) e Venturi 2 (b) 
12 Dispersão dos pontos representativos da correlação entre as vazões observada e calculada para o Venturi 1 (DN 50) (a) e Venturi 2 (DN 75) (b)

13 Erro na vazão calculada em função da vazão observada e da velocidade na tubulação(a) e do sinal digital (b), para o Venturi 1 (DN $50)$

14 Erro na vazão calculada em função da vazão observada e da velocidade na tubulação (a) e do sinal digital (b), para o Venturi 2 (DN 75)

15 Dispersão dos pontos representativos da correlação entre as vazões dos Venturis e o medidor padrão para o Venturi 1 (DN 50) (a) e Venturi 2 (DN 75) (b).

16 Desvios dos dados de vazão fornecidos pelo Venturi, em função da velocidade e da vazão medida pelo GF SIGNET, para o Venturi 1 (DN $50)$

17 Desvios dos dados de vazão fornecidos pelo Venturi, em função da velocidade e da vazão medida pelo GF SIGNET, para o Venturi 2 (DN 75)

18 Perda de carga observada e perda de carga teórica calculada segundo as expressões propostas por 2 autores, em função da vazão, para o Venturi 1 (a) e Venturi 2(b). 


\section{LISTA DE TABELAS}

1 Aplicações típicas dos medidores de vazão geradores de pressão

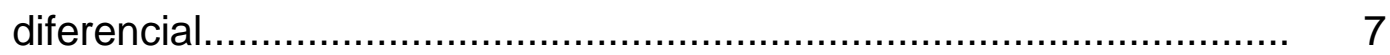

2 Dimensões dos medidores Venturi utilizados................................... 20

3 Coeficientes $\mathrm{K}_{\mathrm{hf}}$ de perda de carga localizada utilizados para os medidores 29

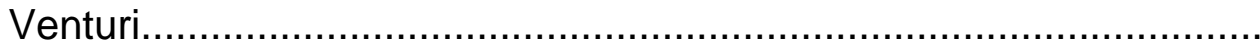

4 Erro percentual médio nas leituras dos Venturis testados por faixa de

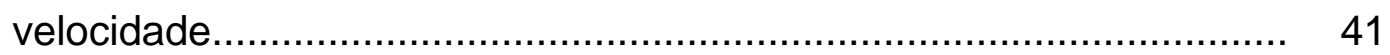

5 Equações de perda de carga dos Venturis $(\mathrm{kPa})$ testados em função

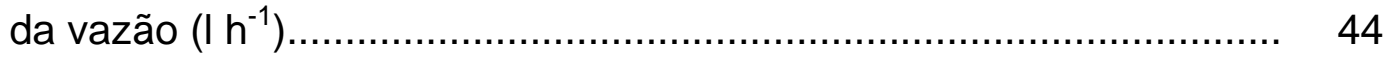

6 Lista de materiais e custos da parte eletrônica dos Venturis construídos..................................................................................... 45

$7 \quad$ Lista de materiais e custos da parte estrutural do Venturi 1 (DN 50)... 46

$8 \quad$ Lista de materiais e custos da parte estrutural do Venturi 2 (DN 75)... 47 


\title{
DESENVOLVIMENTO E AVALIAÇÃO DE TUBOS VENTURI PARA MEDIÇÃO DE VAZÃO
}

\author{
Autor: RUBÉN ALCIDES FRANCO IBARS \\ Orientador: Prof. Dr. TARLEI ARRIEL BOTREL
}

\section{RESUMO}

Visando obter um instrumento de medição de vazão por meio de dispositivos eletrônicos, de fácil construção e baixo custo de materiais, este trabalho se propôs desenvolver e avaliar dois medidores Venturi. Tais medidores foram construídos, calibrados e avaliados no Laboratório de Hidráulica, pertencente ao Departamento de Engenharia Rural da Escola Superior de Agricultura "Luiz de Queiroz", da Universidade de São Paulo, localizado no campus de Piracicaba. A parte cilíndrica dos medidores foi construída com tubulação soldável de PVC, com um diâmetro principal (D) nominal de $50 \mathrm{~mm}$ para o Venturi 1 (DN 50) e de $75 \mathrm{~mm}$ para o Venturi 2 (DN 75); o diâmetro nominal das gargantas (d) foi de 32 e $40 \mathrm{~mm}$ para os Venturis 1 e 2, respectivamente. Os cones convergentes e divergentes foram construidos em resina plástica reforçada com fibra de vidro. Os ângulos utilizados foram de $21^{\circ}$ e $10^{\circ}$, para as seções convergente e divergente respectivamente, em ambos os modelos. O sistema de mensuração foi constituído por um sensor diferencial de pressão, um conversor $A D$ (analógico-digital), um microcontrolador, um display digital, uma fonte de alimentação e um regulador de tensão. Para a calibração foram utilizados dados de vazão, obtida pelo 
método volumétrico, e sinal digital em 200 pontos para cada Venturi. A avaliação foi realizada comparando os dados de vazão obtidos pelos medidores construidos, em relação aos valores proporcionados por um sistema de medição de vazão (considerado como padrão), composto por um sensor do tipo rotor e uma unidade controladora. Este sensor é aplicável em tubulações de 15 a $900 \mathrm{~mm}$, com uma faixa de trabalho para velocidades de 0,10 até $6,00 \mathrm{~m} \mathrm{~s}^{-1}$. Para a calibração e avaliação dos Venturis desenvolveram-se programas na linguagem "Tbasic". O custo total dos materiais utilizados na construção dos medidores de vazão foi de $R \$ 220,32$ para o Venturi 1 (DN 50) e $R \$ 242,36$ para o Venturi 2 (DN 75). Os resultados obtidos mostraram que a construção artesanal de tubos Venturi para medição de vazão é viável técnica e economicamente. Após calibração os medidores apresentaram uma boa precisão e exatidão $\left(r^{2}=0,9979\right.$ e $r^{2}=0,9982$ para os Venturis 1 e 2 , respectivamente) nas medidas quando comparadas com o medidor padrão utilizado. A faixa de trabalho dos medidores de vazão, testados em velocidades até $5,95 \mathrm{~m} \mathrm{~s}^{-1}$ para o Venturi 1 e até $3,85 \mathrm{~m} \mathrm{~s}^{-1}$ para o Venturi 2, está de acordo com as velocidades usuais recomendadas para as tubulações de recalque de irrigação. Para ambos Venturis testados, os desvios médios nas leituras foram maiores $(> \pm 2 \%)$ para velocidades inferiores a 1,5 $\mathrm{m} \mathrm{s}^{-1}$. 


\title{
DEVELOPMENT AND EVALUATION OF VENTURIMETERS FOR FLOW MEASUREMENT
}

\author{
Author: RUBÉN ALCIDES FRANCO IBARS \\ Adviser: Prof. Dr. TARLEI ARRIEL BOTREL
}

\section{SUMMARY}

The purpose of this study was to develop and evaluate two Venturimeters in order to obtain a low cost easily construction flow measurement instrument through electronic devices. The devices were constructed, calibrated and evaluated in the Hydraulics Laboratory of the rural Engineering Department/ESALQ. PVC and fiberglass were used to build the Venturimeters, fiberglass was used to construct the convergent and divergent sections. Venturi 1 (DN 50) had a nominal diameter of $50 \mathrm{~mm}$ in the main section and $32 \mathrm{~mm}$ in the reduced section. Venturi 2 (DN 75) was constructed with nominal diameter of $75 \mathrm{~mm}$ for the main section and $40 \mathrm{~mm}$ for the reduced section. The angles for the convergent and divergent sections were of $21^{\circ}$ and $10^{\circ}$, respectively, for both Venturimeters. The measurement system was constituted for a pressure sensor, an analogical/digital converter, a microcontroller, a digital display, a power supply and a voltage regulator. For calibration flow data at 200 points, obtained by volumetric methods, and digital signal were used. The evaluation was carried out using a flow metering system, constituted for a flow sensor, type rotor, and a control unit. The sensor is used in pipes with sizes from 15 to 90 $\mathrm{mm}$, for water speed between 0,10 and $6,00 \mathrm{~m} \mathrm{~s}^{-1}$. Programs in the "Tbasic" 
language were developed to calibrate and to evaluate the devices. The cost of the materials used in the construction was of in order of $R \$ 220,32$ for Venturi 1 (DN 50) and $R \$ 242,36$ for Venturi 2 (DN 75). The results showed that the handly construction of Venturimeters is feasibled technical and economically. After calibration the devices presented good accuracy $\left(r^{2}=0,9979\right.$ and $r^{2}=$ 0,9982 for Venturis 1 and 2, respectively). The work range of the Venturimeters (maximum water speed of 5,95 and 3,85 for Venturi 1 and 2, respectively) is according with the usually recommended speed range for water in irrigation pipes. For speeds lower than $1,5 \mathrm{~m} \mathrm{~s}^{-1}$ the error $(> \pm 2 \%)$ increase for both tested Venturimeters. 


\title{
DESARROLLO Y EVALUACIÓN DE TUBOS VENTURI PARA MEDICIÓN DE CAUDAL
}

\author{
Autor: RUBÉN ALCIDES FRANCO IBARS \\ Orientador: Prof. Dr. TARLEI ARRIEL BOTREL
}

\section{RESUMÉN}

Proponiéndose obtener un instrumento de medición de caudal a por medio de dispositivos electrónicos, de fácil construcción y bajo costo de materiales, este trabajo tuvo por objetivo desarrollar y evaluar dos medidores Venturi. Los medidores fueron construidos, calibrados y evaluados en el Laboratorio de Hidráulica, perteneciente al Departamento de Ingeniería Rural de la Escuela Superior de Agricultura "Luiz de Queiroz", de la Universidad de São Paulo, localizada en el campus de Piracicaba. La parte cilíndrica de los medidores fue construida con tubos soldables de PVC, con un diámetro principal (D) nominal de $50 \mathrm{~mm}$ para o Venturi 1 (DN 50) y de $75 \mathrm{~mm}$ para o Venturi 2 (DN 75), el diámetro nominal de las gargantas (d) fue de 32 y $40 \mathrm{~mm}$ para los Venturis 1 y 2, respectivamente. Los conos convergentes y divergentes fueron construidos utilizando resina plástica reforzada con fibra de vidrio. Los ángulos, para ambos modelos, fueron de $21^{\circ}$ e $10^{\circ}$ para las secciones convergente y divergente, respectivamente. El sistema de medición fue consto de un sensor de presión, un conversor AD (analógico-digital), un microcontrolador, un display digital, una fuente de alimentación y un regulador de tensión. Para la calibración de cada Venturi, fueron usados 200 puntos de 
caudal, obtenido por el método volumétrico, y señal digital. La evaluación fue realizada comparando los datos de caudal proveídos por los Venturis, con los datos proporcionados por un sistema de medición de caudal, compuesto por un sensor de tipo rotor y una unidad controladora. El sensor puede ser utilizado en tuberías de 15 a $900 \mathrm{~mm}$, para velocidades entre 0,10 y 6,00 $\mathrm{m} \mathrm{s}^{-1}$. Para la calibración y evaluación de los Venturis fueron elaborados programas en el lenguaje "Tbasic". El costo total de los materiales utilizados para la construcción de los medidores de caudal fue de $\mathrm{R} \$ 220,32$ para el Venturi 1 (DN 50) y $\mathrm{R} \$ 242,36$ para el Venturi 2 (DN 75). Los resultados obtenidos mostraron que es viable técnica y económicamente la construcción artesanal de tubos Venturi para medición de caudal. Después de la calibración los medidores presentaron una buena precisión y exactitud $\left(r^{2}=0,9979\right.$ y $r^{2}=$ 0,9982 para los Venturis 1 y 2 , respectivamente) en las medidas en relación con el medidor padrón utilizado. El rango de trabajo de los Venturis construidos, evaluados en velocidades de hasta $5,95 \mathrm{~m} \mathrm{~s}^{-1}$ para el Venturi 1 y hasta $3,85 \mathrm{~m}$ $\mathrm{s}^{-1}$ para el Venturi 2, está de acuerdo con las velocidades usualmente recomendadas para las tuberías de recalque en riego. Para ambos Venturis testados, los desvíos medios en las lecturas fueron mayores ( $> \pm 2 \%)$ para velocidades inferiores a $1,5 \mathrm{~m} \mathrm{~s}^{-1}$. 


\section{INTRODUÇÃO}

Na América do Sul a irrigação é responsável pelo uso de quase $60 \%$ da água doce, concorrendo com outras atividades, como a industrial, domestica, a hidroelétrica e a recreativa entre outras. A concorrência faz necessária uma otimização do uso dos recursos disponíveis visando atingir uma maior eficiência no uso e manejo da água. Porém, para se obter esse aumento na eficiência é preciso implementar sistemas de controle e medição da água.

Denomina-se Hidrometria ao estudo dos métodos de medição de vazão, e dentre as diversas alternativas propostas, algumas precisam de equipamentos sofisticados e caros, ao passo que existem também aquelas que são simples e baratas.

Para a medição de vazão nos condutos forçados, destaca-se o uso de diafragmas, bocais e medidores Venturi, todos originados da aplicação do teorema de Bernoulli, que indiretamente permitem a determinação de vazões por meio da medição do diferencial de pressão em seções de áreas diferentes (Denículi, 1990).

O medidor Venturi se constitui em um dos métodos mais utilizados para a medição de vazão, cujo princípio de funcionamento, está baseado nas teorias desenvolvidas pelo sábio italiano do mesmo nome. Esse dispositivo apresenta vantagens em relação a outros dispositivos como os do tipo molinete, por ser mais preciso, e em relação aos diafragma e bocais, por ocasionar menor perda de carga. Ele é utilizado para medição de vazão em instalações industriais (tratamento de água, condução de gases e produtos corrosivos) e 
pode ser construído utilizando-se diversos materiais como: aço, bronze, alumínio, ferro, PVC e resina plástica reforçada com fibra de vidro, entre outros.

A mistura de uma matriz plástica com fibras de vidro fornece um material estrutural leve, que oferece numerosas vantagens na construção de peças em grande ou pequena escala, oferecendo resistência mecânica, resistência à corrosão e leveza, assim como economia de transporte, manuseio e instalação.

Segundo Vilela et al. (2003b) a evolução da eletrônica e a expansão do mercado têm possibilitado o acesso a instrumentos que antigamente eram disponíveis apenas em avançados centros de pesquisa. A Engenharia Agrícola tem se beneficiado desse avanço tecnológico, seja no desenvolvimento de novos equipamentos ou na adaptação dos já desenvolvidos em outras atividades, para uso na agricultura.

Os microcontroladores disponíveis no mercado possuem um grande potencial de aplicação na agricultura, existindo unidades compactas com preços acessíveis, possibilitando a automação, com o controle do funcionamento hidráulico da irrigação por meio do uso de sensores de pressão e/ou vazão.

Visando se obter um instrumento de medição de vazão utilizando dispositivos eletrônicos, de fácil construção e baixo custo de materiais, este trabalho teve como objetivo construir, calibrar e avaliar dois medidores Venturi. 


\section{REVISÃO DE LITERATURA}

\subsection{Medição de água na agricultura}

Todo projeto relacionado à utilização ou manejo da água tem como ponto de partida o conhecimento ou estimativa do volume da água disponibilizada na unidade de tempo. Seria muito arriscado iniciar qualquer tipo de projeto baseado em uma estimativa duvidosa da disponibilidade de água, razão pela qual há necessidade de se conhecer o valor da vazão disponível ao projeto. $\mathrm{O}$ capítulo da Hidráulica que trata do estudo dos métodos de medição de vazão é denominado Hidrometria (Leopoldo \& Souza, 1979).

A Hidrometria, quando encarada do ponto de vista mais amplo, ou seja, o estudo das variáveis envolvidas nos fenômenos hidráulicos, é uma das partes mais importantes da Hidráulica, justamente porque ela cuida de questões tais como medidas de profundidade, de variação do nível da água, de seções de escoamento, de pressões, de velocidade e vazões, entre outras. As determinações de vazão realizam-se para diversos fins. Entre eles, citam-se sistemas de abastecimento de água, estudos de lançamentos de esgotos, instalações hidroelétricas, obras de irrigação, etc (Azevedo Netto et al., 1998).

Com os conhecimentos atuais das relações solo-água-clima e planta, é possível e desejável que os sistemas de irrigação sejam calculados de modo a aplicar as quantidades necessárias de água. Para tanto, é preciso que se tenham meios para a medição da água a ser aplicada (Bernardo, 1995).

De acordo com Rogers et al. (2003) a irrigação é a atividade que mais utiliza água doce no mundo, em muitas situações concorrendo com outras 
atividades, como o uso domiciliário, industrial, recreativo, etc. A concorrência e a limitada água disponível obriga a um melhoramento do manejo da água, porém, sem uma medição adequada esta tarefa torna-se difícil. Com a medição da água são obtidos dados necessários para determinar a eficiência da irrigação, melhorar o manejo da irrigação, monitorar o rendimento das bombas, etc.

Para Baum et al.(2003) a demanda de água pela agricultura, indústria, uso urbano e atividades recreativas, está aumentando. A demanda crescente exige manejo adequado e conservação dos limitados recursos hídricos. Medidores de vazão adequadamente selecionados, e com uma manutenção correta permitem medidas precisas do fluxo de água, o que vem se tornando muito importante.

Uma medição precisa da vazão é essencial para garantir uma distribuição eqüitativa da água dentro de uma área irrigada, o que se torna fundamental quando estão envolvidos vários os usuários. Um bom manejo do recurso hídrico disponível é dependente da quantificação do mesmo com técnicas precisas de medição. Outorgas de água e procedimentos de manejo requerem freqüentemente a instalação de instrumentos de medição e controle da vazão (Hill, 2003).

\subsection{Tipos de medidores de vazão}

Segundo Lee (2003) a necessidade de quantificar o fluxo de líquidos tem sido reconhecida desde o inicio da civilização e com o avanço da mesma. A demanda por suprimento de água, irrigação, navegação e energia contribuiu para o desenvolvimento de técnicas de medição de nível, vazão e volume de água. Muitas das teorias básicas da hidráulica de medição foram desenvolvidas nos séculos XVII e XVIII, por cientistas como Torricelli, Pitot, Woltman e Venturi. Desde o século XIX até a atualidade a evolução dos medidores acompanhou o desenvolvimento tecnológico. 
De modo geral, a maioria dos métodos propostos baseiam-se na variação do nível de água, no caso dos condutos livres, ou ainda na variação da pressão, no caso dos condutos forçados (Leopoldo \& Souza, 1979).

Para medição de grandes vazões em condutos fechados utilizam-se principalmente três tipos de medidores: 1) por diferencial de pressão; 2) tipo turbina; 3) estáticos ou eletrônicos. Em relação ao primeiro tipo, três medidores podem ser incluídos nesta categoria: tubos Venturi, bocais e placas de orifício. O primeiro tem sua aplicação mais difundida para as tubulações de grande diâmetro e vazão (Programa Nacional de Combate ao Desperdício de Água, 2003).

O instrumental para medição de vazão é muito diversificado, mas devido à facilidade de medição, diversos autores e pesquisadores utilizam processos de medida do tipo diferencial de pressão (Martinez et al., 2003).

Os medidores do tipo diferencial de pressão, constituem cerca de 50\% dos equipamentos utilizados em condutos forçados. O Venturi é o medidor com melhor desempenho entre os seus similares, na categoria de medidores de obstrução (Schneider, 2003). A Figura 1 apresenta os três medidores de vazão por diferencial de pressão mais usados (Tesla, 2003).

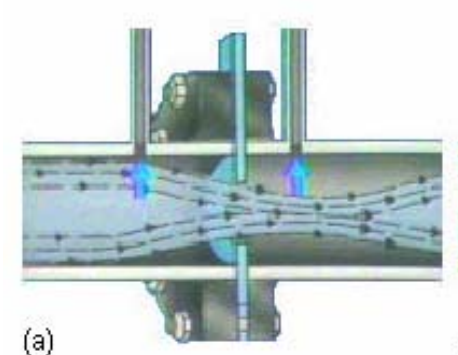

(a)

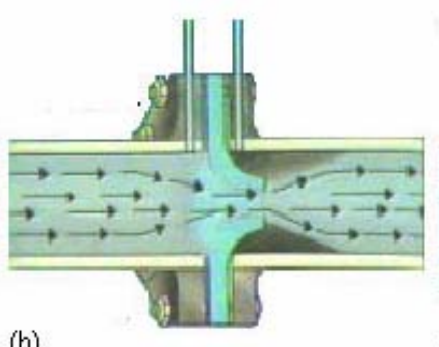

(b)

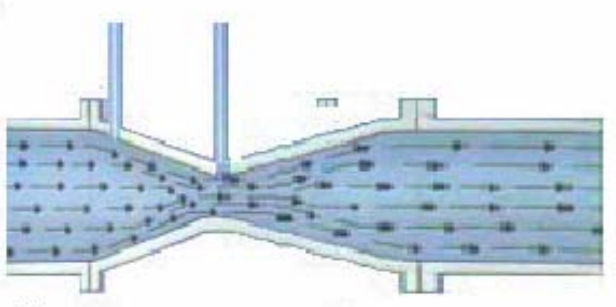

(c)

Figura 1 - Medidores de vazão por diferencial de pressão: orifício (a), bocal (b), Venturi (c)

Os medidores diferenciais são dispositivos que promovem uma redução na seção de escoamento de uma tubulação, de modo a produzir uma diferença 
de pressão, em conseqüência do aumento da velocidade (Azevedo Netto et al., 1998).

Uma importante consideração válida para todos os elementos baseados na aplicação do teorema de Bernoulli é sua sensibilidade ao regime de fluxo, recomendando uma velocidade uniforme em toda a seção, ou em outras palavras, o número de Reynolds deve ser maior do que 10000 (Aguila, 2003).

Estima-se que na atualidade pelo menos $75 \%$ dos medidores de vazão industriais sejam dispositivos de pressão diferencial. Dentre as vantagens destacam-se a construção simples, não possuindo partes móveis e com funcionamento de fácil entendimento; não são caros, comparado a outros tipos de medidores de vazão; podem ser utilizados para a maior parte dos fluidos, existindo muitas publicações sobre as aplicações potenciais. As principais desvantagens são: amplitude de medição menor que outros tipos de medidores; sinal de saída não linear com a vazão; necessidade de trechos compridos de tubulação para a montagem; precisão menor que a de medidores mais modernos (Gutiérrez, 2003).

De acordo com Ullmann et al. (1998) as placas de orifício são de fácil construção e de custo relativamente baixo, quando comparadas com o tubo Venturi, que é de construção mais complexa e custo relativo maior. O bocal fica em uma situação intermediária. As placas de orifício apresentam perda de carga residual maior que os Venturis; a perda de carga do bocal padrão é também maior que a apresentada pelo Venturi, porém menor que a ocasionada pelas placas. Na Figura 2 Gutiérrez (2003) apresenta a perda de carga em porcentagem do diferencial de pressão em função da razão entre o diâmetro da seção contraída e o diâmetro da seção plena (d/D). 


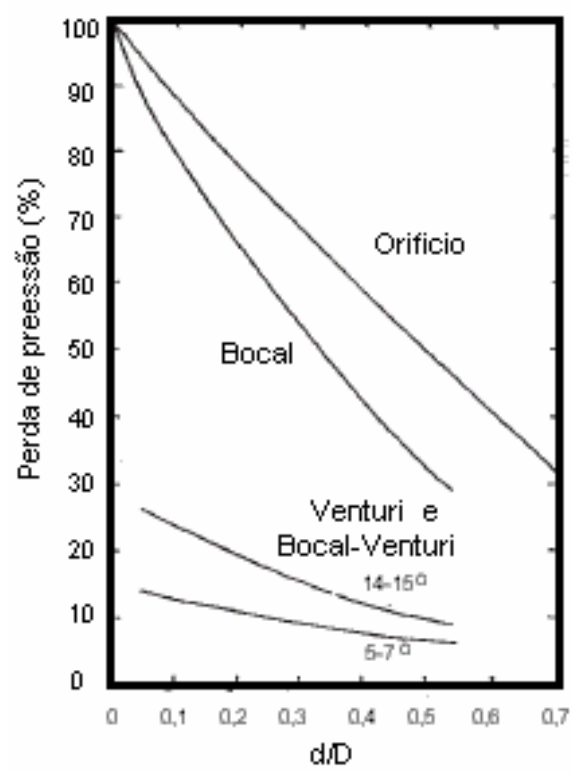

Figura 2 - Perda de carga em porcentagem do diferencial de pressão vs. relação entre o diâmetro da garganta (d) e a tubulação principal (D)

Na Tabela 1 são apresentadas algumas das principais características dos medidores de vazão por diferencial de pressão.

Tabela 1. Aplicações típicas dos medidores de vazão geradores de pressão diferencial

\begin{tabular}{|c|c|c|c|c|c|}
\hline \multirow[t]{2}{*}{ Medidor } & \multirow{2}{*}{$\begin{array}{c}\text { Diâmetro } \\
\text { (polegadas) }\end{array}$} & \multicolumn{4}{|c|}{ Líquidos } \\
\hline & & Limpo & Viscoso & Sujo & Corrosivo \\
\hline $1 / 4$ circulo & $>1 \frac{1 / 2}{2}$ & A & A & $B$ & $B$ \\
\hline 을 Entrada cônica & $>1 \frac{1 / 2}{2}$ & $A$ & $A$ & $B$ & $B$ \\
\hline Ex Excêntrico & $>2$ & B & C & A & B \\
\hline Venturi & $>2$ & $A$ & $B$ & B & B \\
\hline Bocal & $>2$ & A & B & B & B \\
\hline
\end{tabular}

$\mathrm{A}=$ recomendado $\mathrm{B}=$ normalmente aplicado $\mathrm{C}=$ não recomendado.

Fonte: BRINGER (2003). 
Para Rogers \& Black (2003), dentre os medidores de vazão por diferencial de pressão, o venturímetro é o que provoca a menor perda de carga, sendo consequentemente a opção mais recomendável quando existe limitação na energia a ser dispendida.

\subsection{Medidor Venturi}

O medidor Venturi é um aparelho que foi desenvolvido por Clemmens Herschel, em 1881, que leva o nome de G.B. Venturi, um filósofo italiano que foi o primeiro hidráulico a experimentar tubos divergentes (Azevedo Netto et al. 1998).

Uma das formas indiretas de medição de vazão consiste em usar outras variáveis físicas geradas pelo fluido, como queda de pressão, velocidade, força, etc., e por médio da medição da variação destas variáveis, determinar o valor da vazão. Normalmente a medição da vazão efetua-se com elementos que medem o diferencial de pressão, e nessa categoria encontra-se o Venturi, que deve ser de preferência utilizado em posição horizontal (Tesla, 2003).

O tubo Venturi pertence à categoria dos elementos primários geradores de pressão diferencial e pode operar com líquidos, gases e vapor, sendo instalado em série com a tubulação. É aplicado nas medições de ar de combustão de caldeiras, gases de baixa pressão onde se requer perda de carga permanente reduzida e, pelo mesmo motivo, para medição de água em grandes dutos (Delmée, 1982).

De acordo com Spink (1967) e Bringer (2003) o medidor Venturi é considerado um dos melhores tipos de medidor de vazão de fluidos com alta concentração de sólidos, não possuindo obstáculos à passagem do fluído, ou seja, não causando retenção de partículas. O medidor Venturi tem sido freqüentemente utilizado em laboratório para calibrar outros instrumentos. 
Segundo Aguila (2003) os Venturis são utilizados normalmente em tubulações de grande diâmetro, onde seu preço, mesmo que seja relativamente alto, pode ser compensado por oferecer vantagens sobre outras opções. As vantagens que apresenta são sua durabilidade, baixa perda de carga e trechos relativamente curtos de tubulação para sua montagem.

No passado o custo do medidor Venturi limitou o uso do equipamento em grande escala nos sistemas de irrigação. A demanda por instrumentos precisos para a medição de vazão em sistemas pressurizados finalmente pode ocasionar o aumento do uso deste aparelho (United States Department of the Interior - Bureau of Reclamation, 2003).

Segundo Delmée (1982) e Olalla (2003) os tubos Venturi podem ser fabricados usando-se qualquer material, desde que sejam realizados de acordo as dimensões recomendadas. De acordo com este segundo autor, o medidor Venturi com cone de fundição é mais utilizado em tubulações com diâmetro de até $800 \mathrm{~mm}$ e para tubulações com maiores diâmetros utilizam-se chapas de metal soldadas. Outros materiais usados na fabricação são: aço inoxidável, níquel, bronze, fibra de vidro, policloreto de vinil, titânio, etc.

Para Delmée (1982), dependo do material e do tipo de construção o Venturi pode ser utilizado em tubulações de 50 a 1200 mm, recomendando a utilização do Venturi clássico com cone convergente usinado, em tubulações de 50 a $250 \mathrm{~mm}$, e a utilização do Venturi clássico com cone convergente em chapa bruta soldada, em tubulações de 200 a $1200 \mathrm{~mm}$.

Segundo Olalla (2003) o medidor Venturi é normalmente usado em tubulações com diâmetro de 100 a 800 mm, para medição de vazões de líquidos de $5 \mathrm{~m}^{3} \mathrm{~h}^{-1} \mathrm{a} 10^{6} \mathrm{~m}^{3} \mathrm{~h}^{-1}$.

Os venturímetros comerciais de menor tamanho são feitos em latão ou bronze e são disponíveis para tubulações maiores que $50 \mathrm{~mm}$ de diâmetro. Para dimensões maiores pode ser utilizado aço fundido. Em medidores de grande tamanho foi utilizado concreto com as partes cônicas recobertas internamente com metal. Alguns modelos de Venturi têm sido construídos 
usando concreto pré-moldado e plástico (United States Department of the Interior - Bureau of Reclamation, 2003).

De acordo com Contreras et al. (2003) o tubo Venturi permite a medição de vazões $60 \%$ superiores aos da placa de orifício, nas mesmas condições de trabalho, e com uma perda de carga de apenas 10 a $20 \%$ do diferencial de pressão. O custo do Venturi é de cerca de 20 vezes o de um diafragma, porém, propicia uma precisão maior.

O tubo Venturi combina dentro de uma unidade simples, uma curta garganta cilíndrica entre duas seções cônicas de maior diâmetro, sendo a primeira convergente e a segunda divergente. Seu objetivo é acelerar o fluído e temporariamente baixar sua pressão. A recuperação da pressão em um tubo Venturi é bastante eficiente, sendo seu uso recomendado quando se deseja uma maior recuperação de pressão (menor perda de carga) e quando o fluido medido carrega sólidos em suspensão (Galli \& Onofre, 2003).

A American Society of Mechanical Engineers ${ }^{1}$ (ASME), citada por Feitosa Filho (1998), recomenda para o medidor de vazão tipo Venturi clássico um ângulo da seção convergente de $21^{\circ}$ e para seção divergente, entre 5 a $7^{\circ}$.

Segundo Leopoldo \& Souza (1979), Losada (1988) e Denículi (1990), o medidor Venturi compõe-se de uma seção à montante do mesmo diâmetro da tubulação, seguido de uma seção cônica convergente, uma garganta cilíndrica e de uma seção cônica gradualmente divergente, que leva a uma seção cilíndrica com a medida do tubo original. A seção convergente deve ter um ângulo que gira em torno de $20^{\circ}$ e a divergente um ângulo em torno de $5^{\circ}$ a $7^{\circ}$.

Delmée (1982) recomenda adotar para o cilindro de entrada um comprimento mínimo igual ao diâmetro da tubulação. A parte convergente deverá ser em tronco de cone com um ângulo de $21^{\circ}\left( \pm 1^{\circ}\right)$. O comprimento do cone convergente é aproximadamente 2,7 vezes a diferença entre o diâmetro

\footnotetext{
${ }^{1}$ AMERICAN SOCIETY OF MECHANICAL ENGINEERS. Fluid meters: their theory and application. ASME: New York, 1959. 203 p.
} 
da tubulação principal e o diâmetro da garganta. A garganta deverá ser cilíndrica com um diâmetro entre 0,4 e 0,75 do diâmetro principal e um comprimento mínimo igual ao diâmetro. O cone divergente deverá ter um ângulo compreendido entre 7 e $15^{\circ}$ pois quanto menor o ângulo, maior será a recuperação de pressão após da seção divergente.

De acordo com De Paco (1993) o diâmetro da garganta deve estar compreendido entre 0,25 e 0,75 vezes o diâmetro da tubulação principal, sendo muito freqüente o dimensionamento com a relação 0,5 . Os ângulos de $20^{\circ}$ e de $5^{\circ}$ para a convergência e divergência, respectivamente, foram utilizados originalmente por Hershel, embora na atualidade venham se utilizando, para a medição de vazão ângulos de $30^{\circ}$ e de $14^{\circ}$, respectivamente, mesmo produzindo perdas de cargas superiores, porém diminuindo os custos, devido ao seu menor comprimento.

Zarate (1995) utilizou ângulos convergentes de 15 e $14^{\circ}$ e ângulos divergentes de 14 e $12^{\circ}$, para construir 2 injetores de fertilizante do tipo Venturi, de 25 e $32 \mathrm{~mm}$, respectivamente.

Segundo Azevedo Netto et al. (1998) o diâmetro da garganta geralmente estará compreendido entre $1 / 4$ a $3 / 4$ do diâmetro da tubulação, sendo 0 medidor Venturi fabricado em dois tipos: a) longo (Hershel), b) curto (Orivent). Os comprimentos dos tubos longos são geralmente compreendidos entre 5 e 12 vezes o diâmetro da tubulação e nos curtos a relação é de 3,5 até 7 vezes o diâmetro.

Segundo Zarate \& Botrel (2001), nos medidores Venturi, o diâmetro de garganta é geralmente $1 / 3$ do diâmetro da tubulação principal. A seção convergente pode ter um comprimento de 2,5 vezes o diâmetro da tubulação, o qual corresponde a um ângulo de $15^{\circ}$ e no divergente pode apresentar um comprimento de 7,5 vezes o diâmetro da tubulação, o que forma um ângulo de $5^{\circ}$.

A Figura 3 apresenta a composição típica do medidor Venturi (Hyperphysics, 2003). 


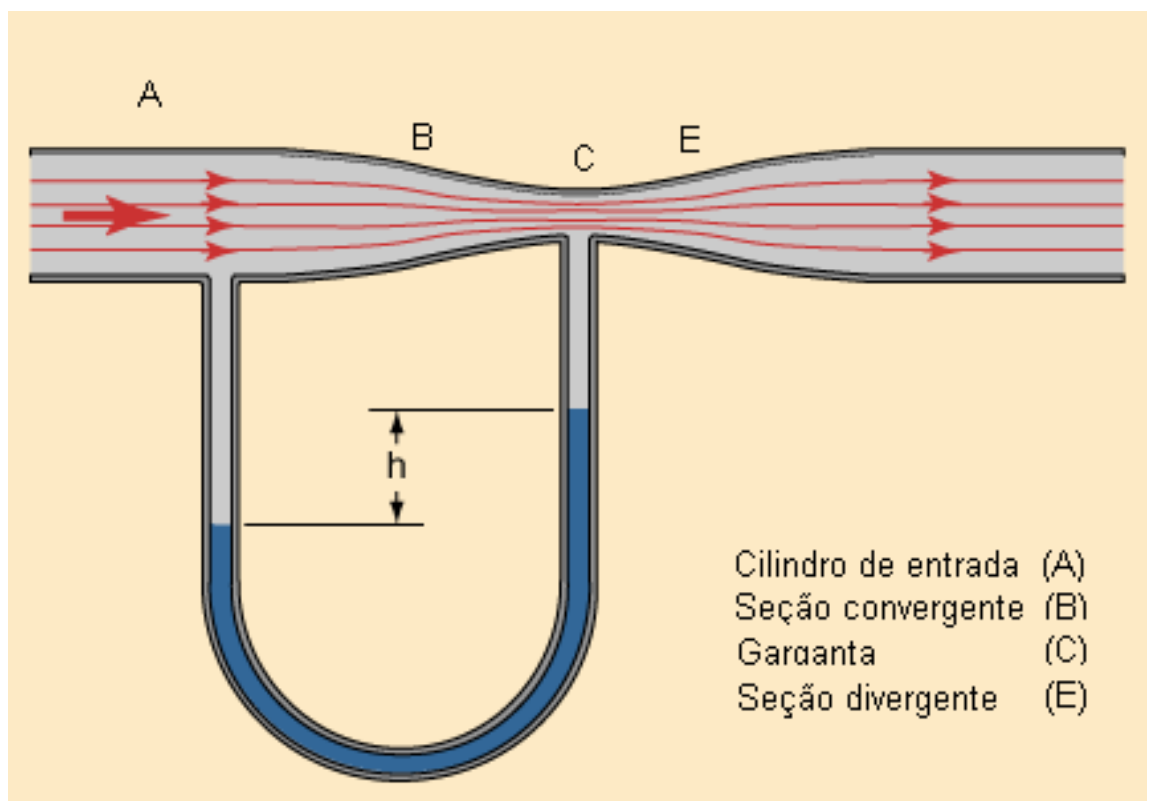

Figura 3 - Composição típica de um medidor Venturi

Segundo Azevedo Netto et al.(1998) a vazão é calculada a partir da diferença de pressão $h$ entre os pontos $A$ e $C$ :

$$
\mathrm{h}=\frac{\mathrm{V}_{\mathrm{C}}^{2}}{2 \mathrm{~g}}-\frac{\mathrm{V}_{\mathrm{A}}^{2}}{2 \mathrm{~g}} \therefore \mathrm{V}_{\mathrm{C}}^{2}-\mathrm{V}_{\mathrm{A}}^{2}=2 \mathrm{gh}
$$

Calculando-se a velocidade no estreitamento, e considerando a equação de continuidade :

$$
\mathrm{V}_{\mathrm{C}}=\mathrm{V}_{\mathrm{A}} \frac{\mathrm{D}^{2}}{\mathrm{~d}^{2}}
$$

Inserindo a equação (2) em (1):

$$
\begin{aligned}
& V_{A}^{2} \frac{D^{4}}{d^{4}}-V_{A}^{2}=2 g h \\
& V_{A}=\frac{\sqrt{2 g} \sqrt{h}}{\sqrt{\left(\frac{D}{d}\right)^{4}-1}}
\end{aligned}
$$

Considerando o coeficiente de descarga $\left(C_{d}\right)$, obtém-se:

$$
\mathrm{Q}=\mathrm{C}_{\mathrm{d}} \mathrm{A}_{\mathrm{A}} \mathrm{V}_{\mathrm{A}}
$$


A equação (5) também pode ser apresentada na forma das equaçoes (6) e (7).

$$
\begin{aligned}
& \mathrm{Q}=3,48 \frac{\mathrm{C}_{\mathrm{d}} \mathrm{D}^{2} \sqrt{\mathrm{h}}}{\sqrt{\left(\frac{\mathrm{D}}{\mathrm{d}}\right)^{4}-1}} \\
& \mathrm{Q}=m \cdot \sqrt{\mathrm{h}}
\end{aligned}
$$

em que:

$\mathrm{Q}$ - vazão, $\mathrm{m}^{3} \mathrm{~s}^{-1}$;

$\mathrm{C}_{\mathrm{d}}$ - coeficiente de descarga, adimensional;

D - diâmetro da tubulação, no ponto A, m;

d - diâmetro da garganta (C), m;

h - diferencial de pressão entre A e C, m.c.a;

$m$ - constante, que engloba as variáveis conhecidas do medidor.

$\mathrm{Na}$ prática os valores de $m$ e o expoente de $h$ são determinados, experimentalmente, por meio de uma regressão do tipo potência.

Segundo Spink (1967) um valor de $C_{d}$ de 0,984 pode ser adotado para todos os diâmetros de medidores Venturis de 50 até $750 \mathrm{~mm}$. Por outro lado, segundo Azevedo Netto et al. (1998), para os medidores Venturi de tipo longo, o valor médio $C_{d}$ esta em torno a 0,975.

A vazão teórica $\left(Q_{t}\right)$ pode ser determinada pela equação (8):

$$
Q_{t}=3,48 \frac{D^{2} \sqrt{h}}{\sqrt{\left(\frac{D}{d}\right)^{4}-1}}
$$

Inserindo a equação (8) na (6), têm se:

$$
\mathrm{Q}=\mathrm{C}_{\mathrm{d}} \mathrm{Q}_{\mathrm{t}}
$$




\subsection{Automação}

Segundo Pizarro (1996), várias são as vantagens da automação na irrigação: 1) possibilidade de melhor controle da freqüência e da quantidade de água aplicada; 2) economia de mão-de-obra e flexibilidade na programação de trabalhos agrícolas; 3 ) controle de outras operações, como a fertirrigação e lavagem de filtros; 4) economia de energia; 5) programação da irrigação em função de vários parâmetros tais como, umidade do solo, evapotranspiração, etc. Testezlaf \& Matsura (1999) também fizeram considerações sobre as melhorias da administração da atividade agrícola por meio da automacão. Segundo estes autores devido ao potencial em aumentar a eficiência do uso da água e da energia, possibilidade de controlar a aplicação de produtos químicos, redução de mão-de-obra e principalmente da necessidade de incrementar a produção agrícola, cresce o interesse do produtor na automatização da operação e consequentemente no manejo da irrigação. Acrescentam ainda que os sistemas automáticos de controle da irrigação se tornaram ferramentas essenciais para a aplicação de água na quantidade necessária e no devido tempo.

O monitoramento automático do manejo da irrigação, embora ainda incipiente no Brasil, constitui-se numa ferramenta importante no controle das aplicações de água para as plantas e na maior eficiência do seu uso, assegurando a sustentabilidade do sistema agrícola irrigado e a preservação do meio ambiente (Carvalho et al., 2001).

Segundo Lopes et al. (1992), com os recentes avanços no campo dos microprocessadores, consegue-se unidades muito compactas a preços interessantes para uso na agricultura. Com esta automação, obtêm-se um progresso qualitativo interessante, com a possibilidade de controlar 0 funcionamento hidráulico da instalação de irrigação por meio de sensores de pressão e vazão. 
De acordo com Pezzin (2003) os sensores são dispositivos que mudam seu comportamento sob a ação de uma grandeza física, fornecendo diretamente ou indiretamente, um sinal que indica esta grandeza. Quando operam diretamente, convertendo uma forma de energia em outra (grandezas não elétricas em grandezas elétricas) são chamados transdutores.

Microcontroladores e microprocessadores são computadores digitais que realizam operações em seqüência sem intervenção humana. As operações são programadas por um programador, que segue uma lista de instruções que compõe a linguagem de programação. Os microcontroladores ou $\mu \mathrm{C}$ são computadores embutidos em circuito integrado. Dentro do microcontrolador podem ser encontrados memória, CPU, entradas e saídas (Angnes, 2003).

Inicialmente, em nível de concepção, o projeto de automatização pode ser dividido em três grupos: transdutores, controladores programáveis e atuadores. Os transdutores são equipamentos que transformam grandezas não elétricas em grandezas elétricas. Os controladores programáveis são equipamentos que recebem as informações dos transdutores e, obedecendo rigorosamente ao software instalado, envia sinais para os atuadores em processo. Os atuadores são basicamente os equipamentos que atuam no processo (Pinto et al., 1997).

Para Pasaye (2003) as aplicações específicas dos microcontroladores são tão variadas, que não é exagerado pensar que o limite é a imaginação do desenhista. Em qualquer situação em que um instrumento digital compacto é capaz de realizar funções como seqüênciamento, codificação/decodificação, monitoramento, aquisição de dados, processamento de sinais, temporização, cálculos matemáticos simples, comunicação, automação, etc., é possível se pensar em um sistema baseado em um $\mu \mathrm{C}$.

Segundo Carrion et al. (2003) no controle automático de um sistema de bombeamento atuam dois componentes básicos: os sensores e os atuadores. Os principais sensores do sistema podem ser sensores de pressão ou medidores de vazão, ou os dois ao mesmo tempo. Estes sensores localizados 
no inicio da linha de impulsão, têm por função, a medida da pressão e/ou vazão de saída em cada momento e conhecer como está desenvolvendo-se o processo de bombeamento. O sinal produzido pelos sensores é enviado a uma unidade de controle digital (microcontrolador ou microprocesador) onde são comparadas com parâmetros predefinidos de funcionamento, e se for necessário, realizam-se os ajustes.

De acordo com Souza (2001), a agricultura irrigada e outras atividades rurais necessitam incorporar as novas tecnologias disponíveis. São muitos os componentes eletrônicos, sensores e microcontroladores que podem ser utilizados na irrigação, sendo tarefa dos profissionais da área identificar as aplicações potênciais destas ferramentas.

De acordo com Angnes (2003) o Basic Step é um microcontrolador nacional, baseado no Basic Stamp, extremamente fácil de se utilizar. Com alimentação de $7,5 \mathrm{~V}$ a $15 \mathrm{~V}$, possui 8 entradas e saídas com capacidade de corrente de 25mA. Com dimensões de $3,5 \mathrm{~cm} \times 3,0 \mathrm{~cm}$, o Basic Step 1, é programado na linguagem "Tbasic" ou "Pbasic". Ambas são similares ao Basic, sendo a primeira em português e a segunda em inglês. Para programar o Basic Step são necessários um microcontrolador Basic Step, uma fonte CC para alimentação do $\mu \mathrm{C}$, o compilador Basic Step, um computador e um cabo de gravação.

De acordo com Vilela et al. (2003a) vários equipamentos de uso agrícola foram desenvolvidos usando o microcontrolador Basic Step. O mesmo é programado serialmente usando a porta paralela do computador desde que seja do tipo IBM PC. O programa logo após ser enviado pelo computador é armazenado na memória EEPROM do $\mu \mathrm{C}$.

Vilela et al. (2003b) construíram e calibraram um manômetro digital, utilizando o microcontrolador Basic Step, um conversor analógico digital e um transdutor de pressão. O custo dos materiais empregados na montagem foi de $\mathrm{R} \$ 201,50$, cerca de $36 \%$ do custo do manômetro digital com menor cotação encontrado no mercado. 
No medidor Venturi, o estrangulamento do escoamento provoca um diferencial de velocidade e pressão. Por meio de sensores ou tomadas pode-se verificar o diferencial de pressão entre os pontos. A cada valor de diferencial de pressão esta associada uma vazão. Atualmente, na medição do diferencial de pressão, têm sido bastante utilizados os transdutores de pressão, existindo diversos tipos. Dentre os tipos principais de medidores, podem ser citados: os piezoelétricos, para medições da pressão nas linhas, e os capacitivos, para medição do diferencial de pressão em Venturis, tubos de Pitot e outros instrumentos similares (Programa Nacional de Combate ao Desperdício de Água, 2003).

Contreras et al. (2003) utilizaram um transdutor de pressão MPX7100 da Motorola para medir o diferencial de pressão de um medidor Venturi e utilizando como interface e controle, um microcontrolador da família microchip 16F87X. Este microcontrolador conta com 5 pontos bi-direcionáveis e 8 canais de conversores analógico-digital de 10 bits.

Mundo et al. (2001) avaliaram um medidor totalizador volumétrico (MTP) para poços com dispositivo do tipo diafragma unido a um computador eletrônico, obtendo resultados satisfatórios, com uma precisão de $\pm 2,5 \%$ em relação à testemunha, um vertedor triangular, previamente calibrado de forma volumétrica. Também foi avaliado um medidor MTP tipo Venturi, com resultados idênticos ao MTP de diafragma, ambos com maior precisão que os medidores do tipo molinete avaliados no laboratório. 


\section{MATERIAL E MÉTODOS}

O experimento foi desenvolvido no Laboratório de Hidráulica, do Departamento de Engenharia Rural da Escola Superior de Agricultura "Luiz de Queiroz", da Universidade de São Paulo, localizada no campus de Piracicaba. Os medidores Venturi foram construídos, calibrados e avaliados neste laboratório, sendo utilizada a estrutura e instrumental do laboratório, como: reservatórios, motobombas, tubulações de condução, medidores de vazão e outros equipamentos.

\subsection{Os Venturis utilizados}

Foram construídos 2 medidores Venturi, sendo as partes cilíndricas dos mesmos em tubulação soldável de PVC, com um diâmetro principal (D) nominal de $50 \mathrm{~mm}$ para o Venturi 1 (DN 50) e de $75 \mathrm{~mm}$ para o Venturi 2 (DN 75); as gargantas (d) foram em diâmetro nominal de 32 e $40 \mathrm{~mm}$ para os venturis 1 e 2, respectivamente. Os cones convergentes e divergentes foram fabricados com resina plástica reforçada com fibra de vidro. Para a construção das seções cônicas utilizaram-se moldes de PVC que posteriormente foram cobertos com a resina e fibra de vidro; estes moldes podem servir para a construção de outros medidores Venturi. Os ângulos foram de $21^{\circ}$ e $10^{\circ}$ para as seções convergente e divergente, respectivamente, nos 2 modelos. Estes valores adotados para os ângulos foram baseados nas dimensões típicas de Venturis citadas por Delmée (1982). Na Figura 4 são apresentados alguns detalhes de materiais e dispositivos usados na construção dos Venturis. 

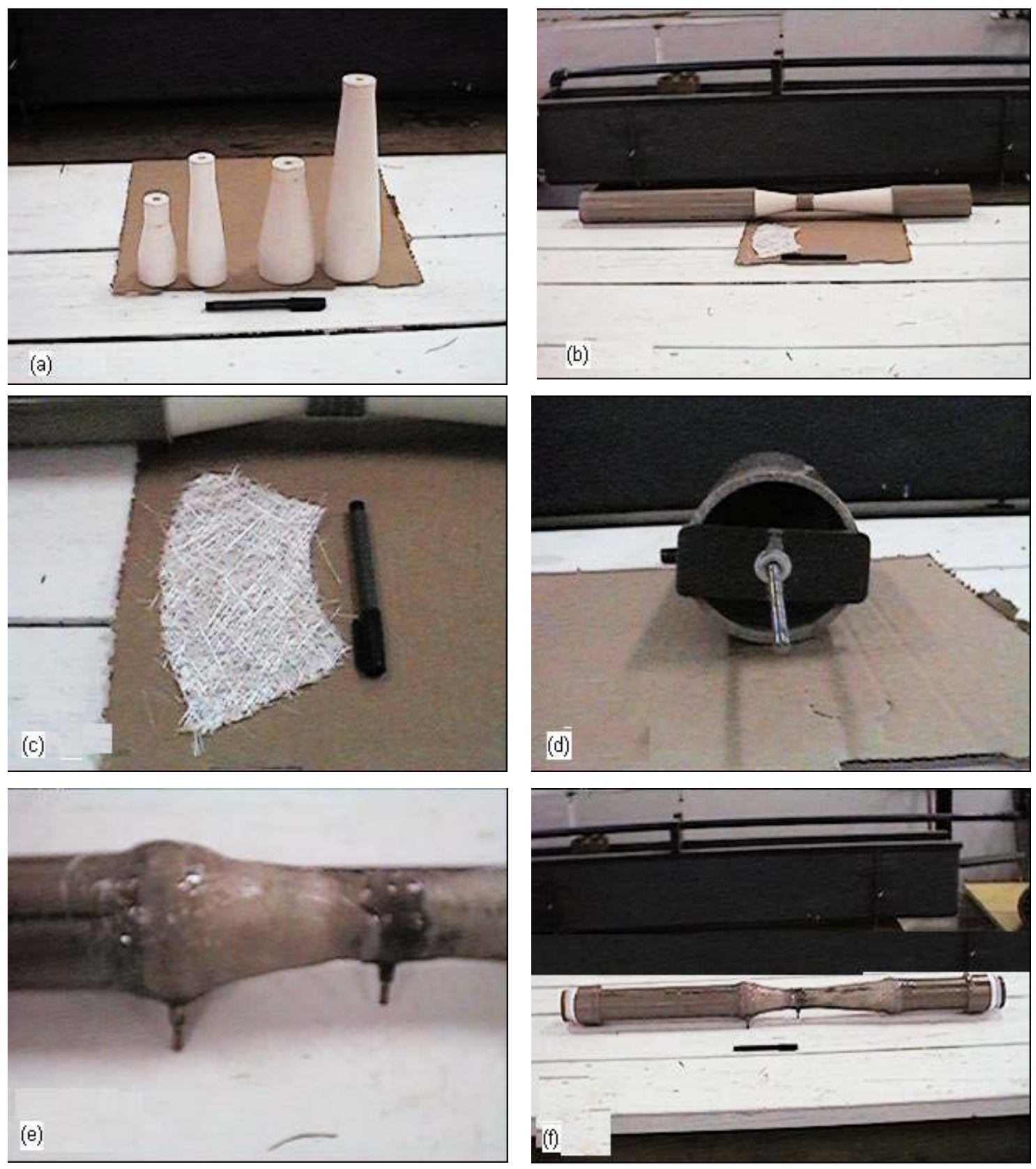

Figura 4 - Materiais utilizados na construção dos tubos Venturi: moldes de PVC (a), tubulação de PVC (b), manta de fibra de vidro (c), sistema de extração das molduras (d), tomadas de pressão (e), Venturi terminado e com os adaptadores roscáveis (f) 
Para determinar o comprimento dos Venturis, considerou-se um comprimento mínimo de 12 vezes o diâmetro nominal da tubulação principal (Azevedo Netto et al., 1998), obtendo-se um comprimento total de 680,28 mm para o Venturi 1 e de $899,00 \mathrm{~mm}$ para o Venturi 2. Na tabela 2 encontram-se as dimensões dos medidores de vazão que foram construídos.

Tabela 2. Dimensões dos medidores Venturi utilizados

\begin{tabular}{ccccccc}
\hline \multirow{2}{*}{ Venturi } & Comprimento & \multicolumn{4}{c}{ Diâmetro } & Relação entre \\
& & \multicolumn{2}{c}{ Principal } & Garganta & diâmetros \\
& & Nominal & Interno & Nominal & Interno & $(\mathrm{d} / \mathrm{D})$ \\
\hline 1 & 680,28 & 50,00 & 44,00 & 32,00 & 27,80 & 0,63 \\
2 & 899,36 & 75,00 & 66,60 & 40,00 & 35,20 & 0,53 \\
\hline
\end{tabular}

Nota: para os dois Venturis utilizaram-se ângulos de $21^{\circ}$ e $10^{\circ}$ para as seções convergentes e divergentes respectivamente.

Nas Figuras 5 e 6 podem ser observadas com maior detalhe as dimensões dos medidores Venturis 1 e 2, respectivamente.

Em cada modelo, no cilindro de entrada (A) e na garganta $(C)$, foram inseridas tomadas de pressão, para permitir a medição do diferencial de pressão entre os dois pontos. A primeira foi instalada antes do cone convergente (B), e a segunda, no centro da garganta (C).

No extremo de cada Venturi foram colados adaptadores roscáveis para facilitar a instalação dos mesmos nas tubulações. 


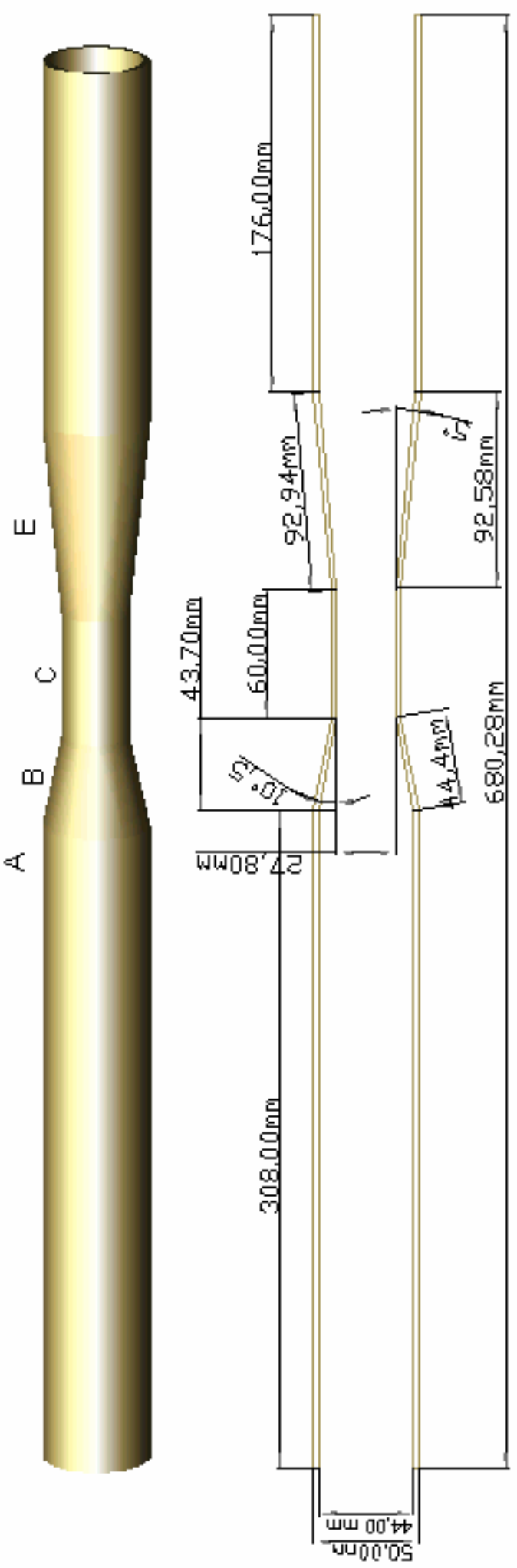

Figura 5 - Dimensões do medidor Venturi 1 (DN 50) 


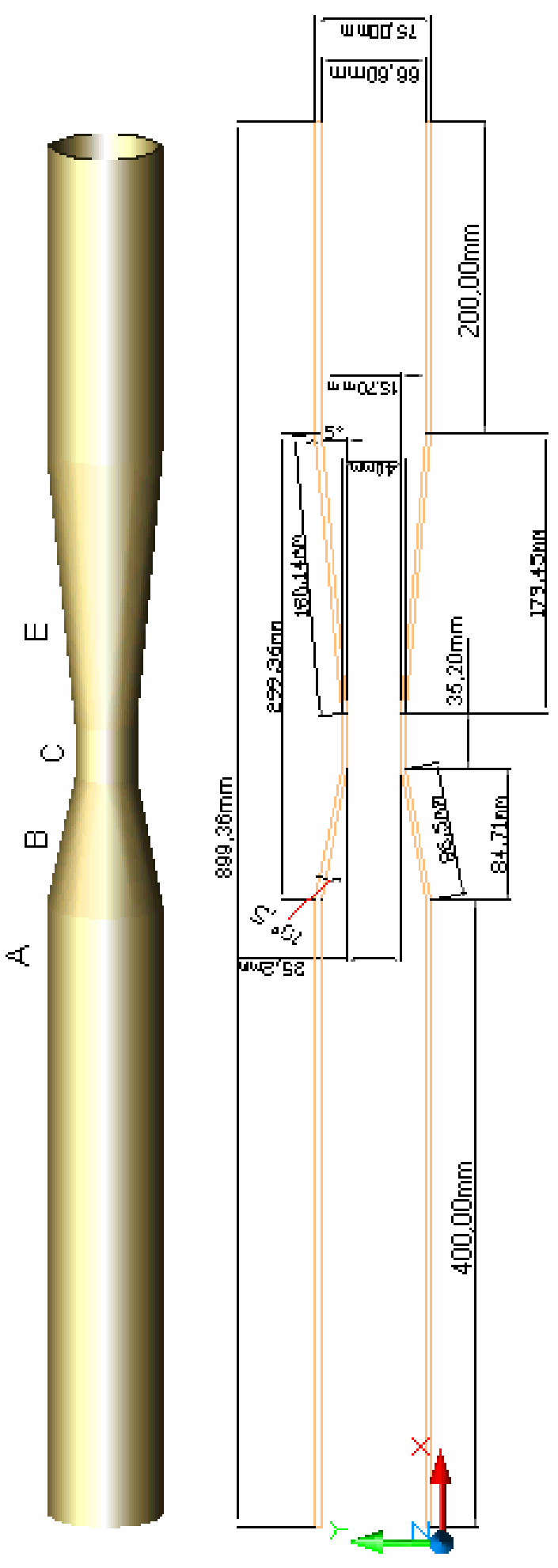

Figura 6 - Dimensões do medidor Venturi 2 (DN 75) 


\subsection{Circuito eletro-eletrônico}

Foram utilizados componentes eletrônicos iguais para ambos Venturis, sendo que no funcionamento dos mesmos, o que os diferenciou foi apenas a programação para a medição de vazão.

O sistema de mensuração foi constituído por um sensor diferencial de pressão, um conversor AD (analógico-digital), um microcontrolador e um display digital, uma fonte de alimentação e um regulador de tensão. Os principais componentes eletrónicos e uma vista geral do sistema são apresentados na Figura 7.

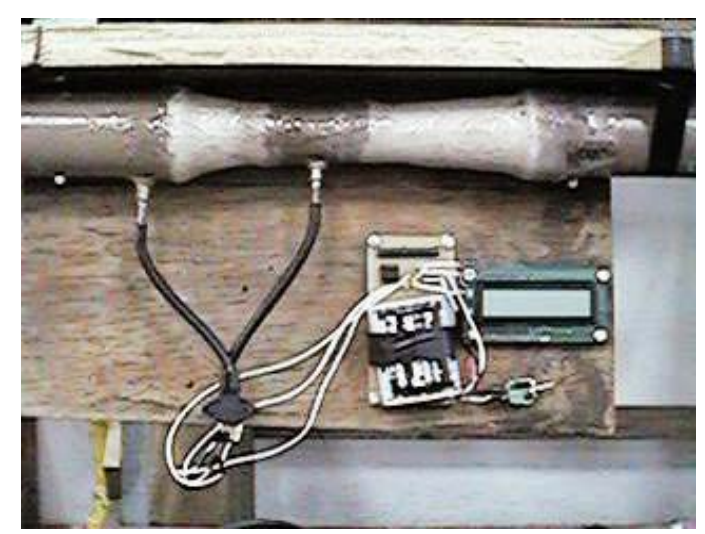

(a)

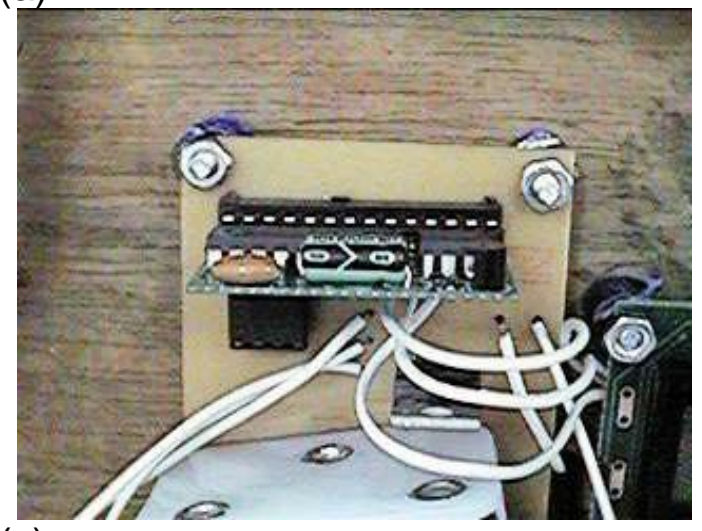

(c)

Figura 7 - Vista geral do medidor Venturi com os componentes eletrônicos (a), transdutor de pressão (b), microcontrolador Basic Step (c), display digital (d) (b)
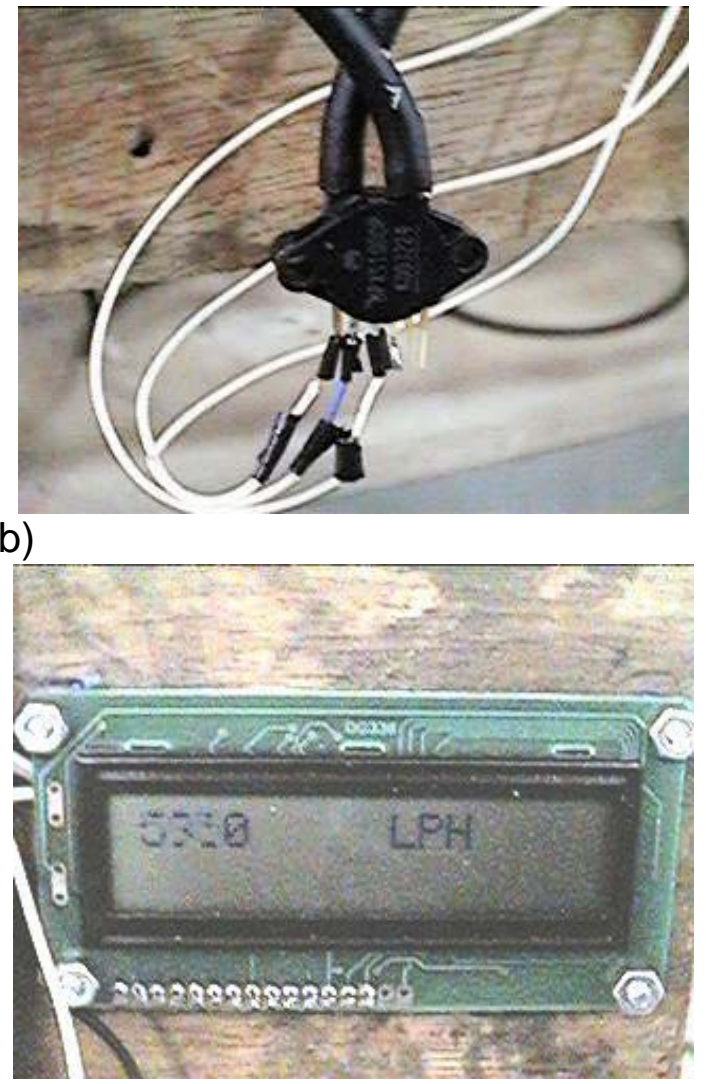

(d) 
Para a medição do diferencial de pressão foi montado um circuito eletroeletrônico em que se utilizaram: um transdutor de pressão Motorola modelo MPX5100, conectado nas tomadas de pressão dos Venturis por meio de microtubos de $4 \mathrm{~mm}$. O fabricante do transdutor informa que o modelo é produzido para atender uma faixa de diferencial de pressão de 0 a $100 \mathrm{kPa}$, com uma precisão de $\pm 2,5 \%$, operando em temperaturas entre 0 e $85^{\circ} \mathrm{C}$, emitindo sinais analógicos de 0,2 a 4,7 Vcc, com uma alimentação de $5 \mathrm{~V}$ (MOTOROLA, 2003). O transdutor foi conectado a um conversor analógicodigital de 1 canal modelo ADC0831 de 8 bits (NATIONAL SEMICONDUCTOR CO., 2003). Um microcontrolador (Basic Step 1) foi empregado para receber e processar os dados de queda de pressão nos medidores Venturi. O Basic Step é um microcontrolador nacional com uma alimentação de 6,5 a $15,5 \mathrm{~V}$, fabricado pela empresa Tato Equipamentos Eletrônicos Ltda. A vazão era apresentada em um display digital com uma alimentação de 5V. O Basic step foi ligado diretamente a uma fonte de $9 \mathrm{~V}(6$ pilhas de $1,5 \mathrm{~V}$ ) sendo que os demais componentes utilizaram um regulador de tensão LM7805, com uma faixa de saída de alimentação de 9 a $24 \mathrm{~V}$ e uma voltagem de saída de $5 \mathrm{~V}$. A programação foi feita posteriormente, de acordo com a necessidade. Utilizaramse programas para calibrar e para avaliar os medidores Venturi e para a programação foi usada a linguagem "Tbasic", sendo o programa armazenado na memória do microcontrolador e executado ao ligar o sistema.

Os componentes foram montados em uma placa de fenolite, desenhada pelo programa Areslite, sendo o software um roteador automático da Labcenter Electronics (1999). O esquema de montagem dos componentes na placa é apresentado na Figura 8. 

(a) Transductor de pressão MPXS100
(b) Conversor AD ADC0831
(c) Basic Step
(d) LCD
(e) Alimentacão $9 \mathrm{~V}$
(f) Regulador de tensão LM7805

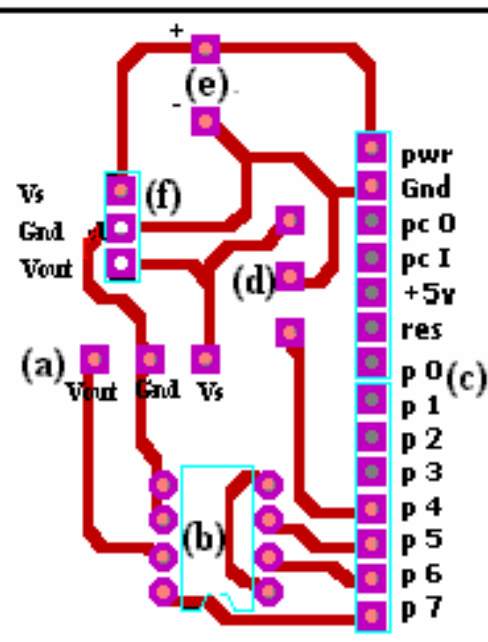

Figura 8 - Esquema da placa de fenolite utilizada para montagem dos componentes eletro-eletrônicos

\subsection{Calibração}

Para calibrar cada medidor Venturi foram feitas 200 leituras de vazão e sinal digital por intermédio da leitura do conversor AD.

Existe uma leitura residual no transdutor de pressão de 200,2 mV, ou seja, um sinal digital de 10,86. A leitura residual foi subtraída de cada leitura do conversor $A D\left(L_{c}\right)$ como apresenta a equação (10).

$$
L_{c}=255-10,86
$$

O Maximo diferencial de pressão, 10 mca, correspondeu a uma leitura do sinal digital de 244,14 (após da subtração), sendo o diferencial de pressão expresso pela equação (11).

$$
h=0,04096 L_{c}
$$

em que:

h - diferencial de pressão, mca;

$L_{c}$ - leitura do conversor AD. 
Substituindo-se a equação (11) na (6) e considerando a conversão da vazão para $L h^{-1}$, o cálculo da vazão pode ser feita pela equação 12:

$$
Q=12,528 \cdot 10^{6} \frac{C_{d} D^{2} 0,2024 \sqrt{L_{c}}}{\sqrt{\left(\frac{D}{d}\right)^{4}-1}}
$$

Pode-se considerar como única variável a leitura do conversor $A D$, de modo que a vazão pode ser expressa pela equação 13:

$$
\mathrm{Q}=\mathrm{K} \sqrt{\mathrm{L}}_{\mathrm{c}}
$$

Substituindo os valores na equação 13 , sem considerar o $C_{d}$, obtiveram-se as equações teóricas (14) e (15) para determinar a vazão dos medidores Venturis 1 e 2, respectivamente:

$$
\begin{aligned}
& \mathrm{Q}=2138,77 \sqrt{\mathrm{L}_{c}} \\
& \mathrm{Q}=3274,21 \sqrt{\mathrm{L}_{c}}
\end{aligned}
$$

onde:

$\mathrm{Q}$ - vazão teórica, $\mathrm{L} \mathrm{h}^{-1}$;

$L_{c}$ - leitura do conversor $A D$.

Para a calibração utilizou-se a equação 13, para se obter um valor médio de $\mathrm{K}$ determinou-se a vazão pelo método volumétrico, sendo feita concomitantemente a leitura do conversor $A D$, através de um programa desenvolvido com esse propósito. A vazão foi determinada pelo método volumétrico, utilizando-se um tanque com uma capacidade de 1045 litros com uma precisão de $100 \mathrm{ml} \mathrm{e} \mathrm{um} \mathrm{cronômetro} \mathrm{com} \mathrm{precisão} \mathrm{de} \mathrm{centésimo} \mathrm{de}$ segundo. $\mathrm{O}$ tanque foi utilizado em faixas de aproximadamente $200 \mathrm{~L}$.

\subsection{Avaliação}

Estabelecido o valor de $\mathrm{K}$, procedeu-se ao desenvolvimento de um programa de medição de vazão para cada modelo, na linguagem "Tbasic", e que fornecia a leitura da vazão em $L h^{-1}$. 
A avaliação dos medidores Venturis foi realizada comparando os dados de vazão obtidos, com os proporcionados por um sistema de medição de vazão fabricado pela GF SIGNET, composto por um sensor de vazão e uma unidade controladora.

Segundo o fabricante (GF SIGNET, 2003a), o sensor tipo rotor é utilizável em tubulações de 15 a $900 \mathrm{~mm}$, com uma faixa de trabalho de velocidade de 0,10 até $6,00 \mathrm{~m} \mathrm{~s}^{-1}$, com uma alimentação de 3,3 a $24 \mathrm{Vcc}$. Para os testes, o sensor foi montado em uma tubulação de 2" roscável. O mesmo foi previamente calibrado segundo as especificações do fabricante e comparado com o método volumétrico. A precisão é de $\pm 1 \%$, requerendo um número de Reynolds mínimo de 4500 para seu funcionamento.

A unidade controladora consistia de um transmissor de vazão 8550 compatível com todos os sensores de saída de freqüência do mesmo fabricante que o sensor, com uma alimentação de 12 a $24 \mathrm{Vcc}$ e uma temperatura de trabalho de -10 a $70{ }^{\circ} \mathrm{C}$ (GF SIGNET, 2003b). 
A Figura 9 apresenta o sensor e o transmissor de vazão, assim como sua montagem típica.

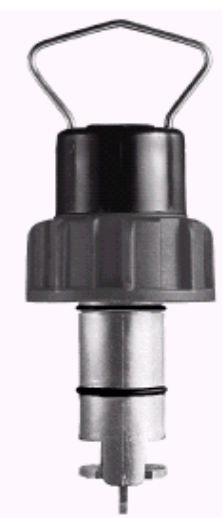

(a)

(c)

(b)

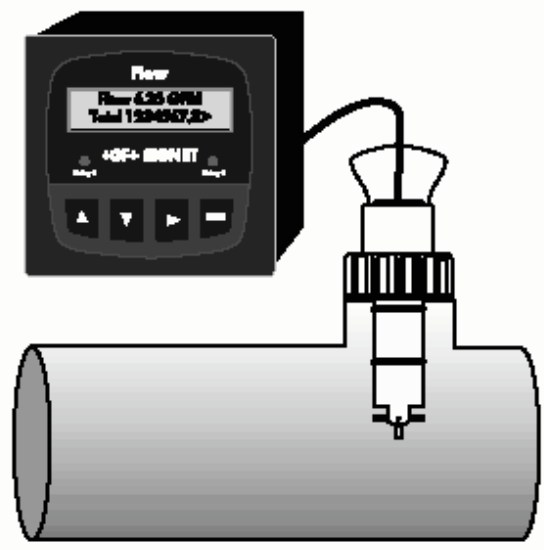

Figura 9 - Sensor de vazão GF SIGNET 2536 (a); transmissor de vazão GF SIGNET 8550 (b); montagem típica dos mesmos (c)

Também foi determinada a perda de carga produzida pelos medidores Venturis, utilizando-se um manômetro diferencial de mercúrio, as leituras do manômetro incluíram as perdas nas conexões com a tubulação. As perdas de carga foram comparadas com a perda de carga teórica, expressa pela equação 16:

$$
h f=K_{h f} \frac{V^{2}}{2 g}
$$

em que:

hf - perda de carga localizada, mca; 
$\mathrm{K}_{\mathrm{hf}}$ - coeficiente que depende da geometria da peça, adimensional;

$\mathrm{V}$ - velocidade média na seção, $\mathrm{m} \mathrm{s}^{-1}$;

$\mathrm{g}$ - aceleração da gravidade, $\mathrm{m} \mathrm{s}^{-2}$.

A perda de carga teórica foi calculada por dois métodos. No primeiro foram utilizados coeficientes $\mathrm{K}_{\mathrm{hf}}$ propostos por Porto (1999), que calcula separadamente a perda de carga localizada em alargamentos e estreitamentos graduais de tubulações, considerando os ângulos e a relação entre o diâmetro principal e o estrangulamento (D/d), as perdas foram posteriormente somadas para obter a perda total. Os cálculos foram baseados na velocidade na seção menor. O segundo método utiliza um valor $\mathrm{K}$ proposto por Azevedo Netto et al. (1998), calculando a perda de carga localizada com base na velocidade na seção maior. Em cada medidor Venturi a perda de carga foi determinada em 40 pontos.

A Tabela 3 mostra os coeficientes de perda de carga localizada utilizados.

Tabela 3. Coeficientes $\mathrm{K}_{\mathrm{hf}}$ de perda de carga localizada utilizados para os medidores Venturi

\begin{tabular}{ccccc}
\hline Modelo & Relação & \multicolumn{3}{c}{${\text { Coeficiente } \mathrm{K}_{\mathrm{hf}}}$} \\
\cline { 3 - 5 } & D/d & Seção convergente $^{1}$ & Seção divergente $^{1}$ & Venturi $^{2}$ \\
\hline Venturi 1 & 1,58 & 0,03 & 0,18 & 2,50 \\
Venturi 2 & 1,89 & 0,05 & 0,36 & 2,50 \\
\hline
\end{tabular}

1 Propostos por Porto, calculo da hf com base na velocidade no estreitamento (1999).

2 Propostos por Azevedo Netto et al. (1998), calculo da hf com base na velocidade na seção maior.

Os coeficientes de descarga para os medidores Venturis foram determinados a partir das equações (9), (14) e (15). 


\section{RESULTADOS E DISCUSSÃO}

\subsection{Calibração}

Na calibração dos medidores Venturi, foram utilizados os dados de vazão medidos e as leituras do sinal digital, com um total de 200 pares de dados para cada Venturi. A vazão determinada pelo método volumétrico e a leitura do conversor AD por meio de um programa na linguagem "Tbasic" (anexo A).

Para o Venturi 1 (DN 50) trabalhou-se na faixa de $1455 \mathrm{~L} \mathrm{~h}^{-1}$ até 32129 $\mathrm{L} \mathrm{h}^{-1}$, com uma velocidade média na seção plena de $0,27 \mathrm{~m} \mathrm{~s}^{-1}$ a $5,87 \mathrm{~m} \mathrm{~s}^{-1}$, com valores de sinal digital entre 0 e 231 e número de Reynolds de 11500 até 247000, considerando o diâmetro principal.

Para o Venturi 2 (DN 75) os valores extremos de vazão usados na calibração foram de $1859 \mathrm{Lh}^{-1}$ e $48333 \mathrm{~L} \mathrm{~h}^{-1}$, a faixa de velocidade foi de 0,15 $\mathrm{m} \mathrm{s}^{-1}$ a $3,85 \mathrm{~m} \mathrm{~s}^{-1}$, com valores de sinal digital compreendidos entre 0 e 240 e número de Reynolds entre 10150 e 248600 , calculados na seção principal.

O ajuste potencial dos dados de vazão em função do sinal digital apresentou um $r^{2}$ de 0,9987 para o Venturi 1 (DN 50) e $r^{2}$ de 0,9984 para o Venturi 2 (DN 75). A Figura 10 apresenta os dados usados para a calibração, assim como as equações potenciais estabelecidas de vazão em função do sinal digital. As equações estabelecidas, na Figura 10, possuem um expoente diferente de 0,5 para o sinal digital, valor que foi fixado na equação (13) para determinar a vazão dos Venturis construídos. Com o expoente definido precisou-se estabelecer o valor da constante $\mathrm{K}$ de cada modelo. 

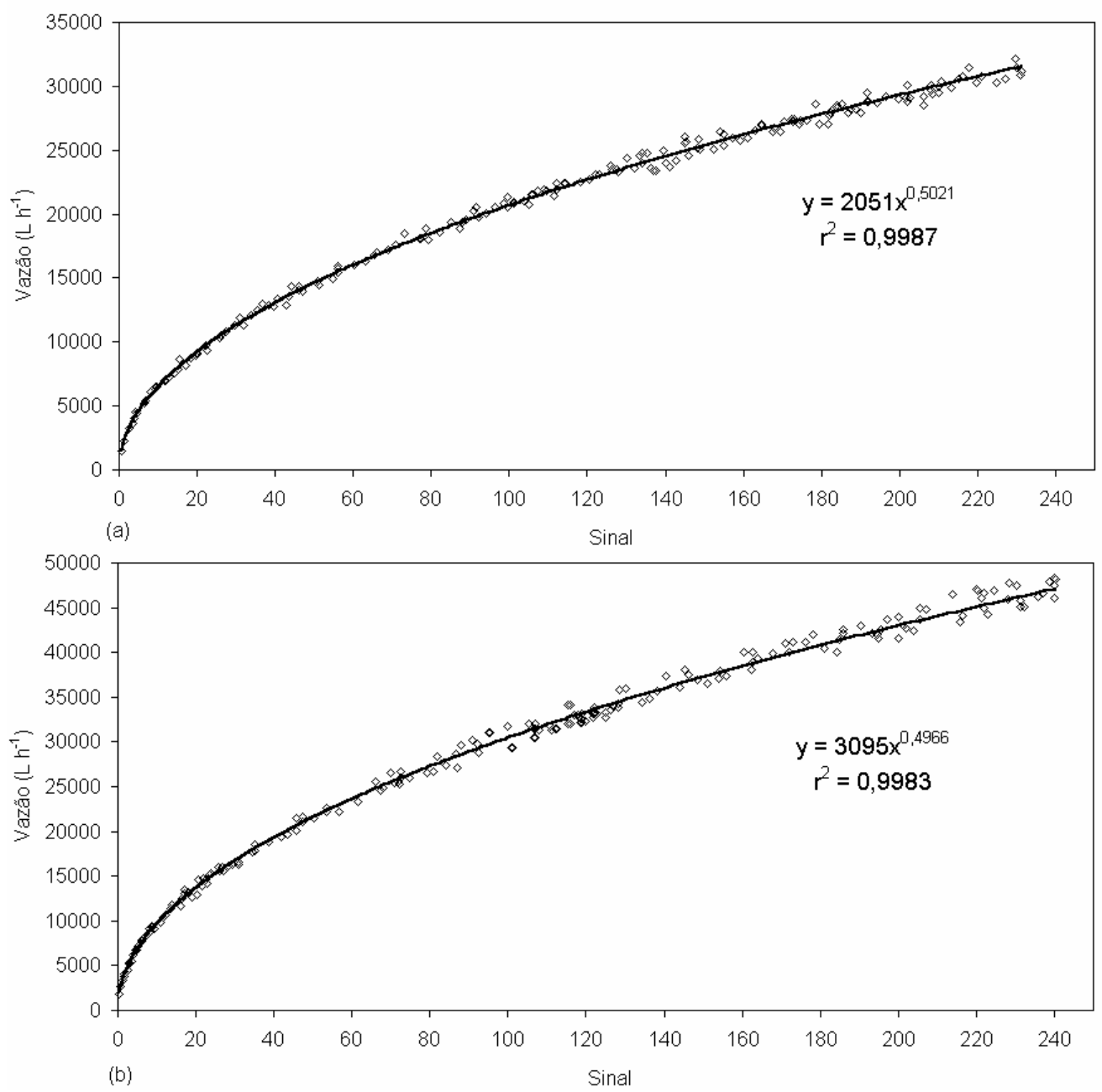

Figura 10 - Dados de vazão vs. sinal digital para o Venturi 1 (a) e Venturi 2 (b)

$\mathrm{O}$ valor da constante $\mathrm{K}$ foi estabelecido por intermédio de uma regressão linear entre a vazão e a raiz quadrada do sinal digital, forçando à reta passar pela origem (coeficiente angular nulo) de forma que o coeficiente angular representa o valor do coeficiente $\mathrm{K}$.

Na Figura 11 são apresentadas as regressões lineares, assim como os valores de K para cada Venturi. 

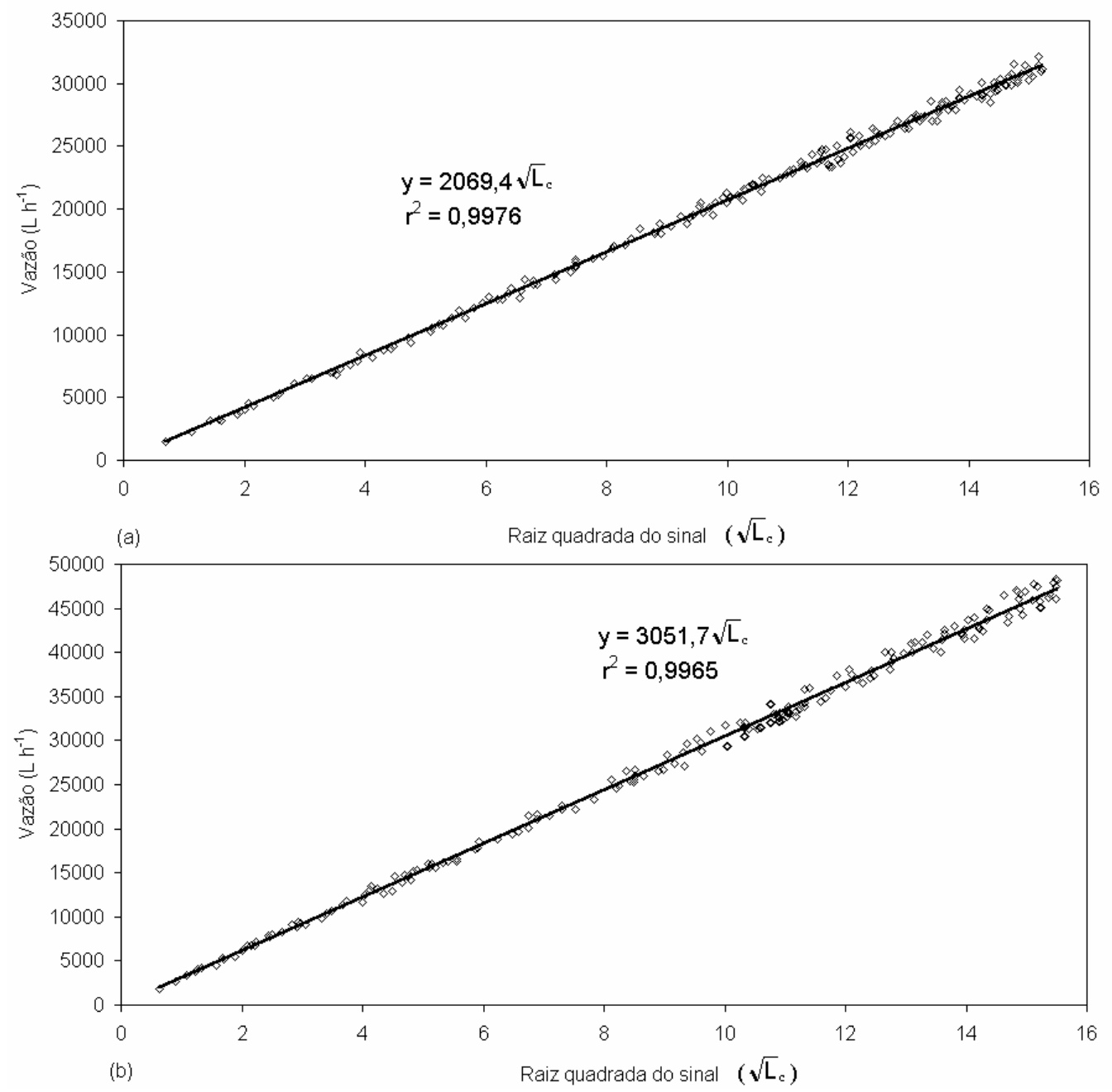

Figura 11 - Valores de vazão vs. raiz quadrada do sinal digital para os Venturi 1 (a) e Venturi 2 (b)

Uma vez determinado o valor da constante $\mathrm{K}$, o mesmo foi aproximado para um valor inteiro, e de esta forma foram estabelecidas a equações (17) e (18) para o cálculo da vazão dos Venturi 1 e 2, respectivamente.

$$
\begin{aligned}
& \mathrm{Q}=2069 \sqrt{\mathrm{L}_{c}} \\
& \mathrm{Q}=3052 \sqrt{\mathrm{L}_{c}}
\end{aligned}
$$

em que:

Q -vazão, L h ${ }^{-1}$;

$L_{c}$ - leitura do conversor AD. 
Com os dados coletados do sinal foi calculada uma nova vazão utilizando a equações 17 e 18. A Figura 12 apresenta a dispersão dos pontos relativos à correlação da vazão calculada e a vazão observada (método volumétrico), em torno da reta 1:1, assim como o coeficiente de determinação $\left(r^{2}\right)$ e o índice de concordância $(d)$.
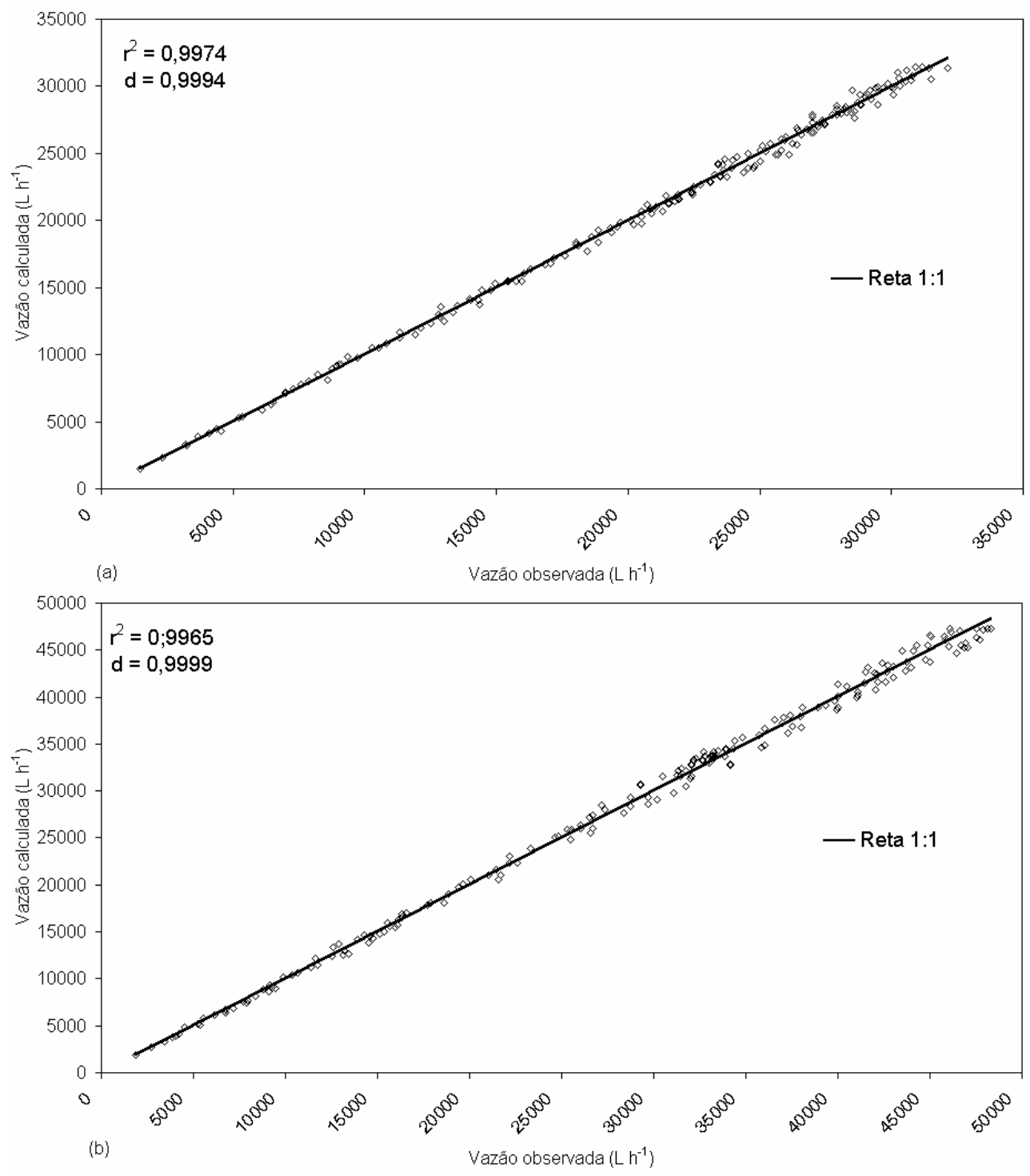

Figura 12 - Dispersão dos pontos representativos da correlação entre as vazões observada e calculada para o Venturi 1 (DN 50) (a) e Venturi 2 (DN 75) (b) 
As correlações apresentam uma alta significância, indicada pelo teste " $\mathrm{t}$ " com um valor de 276 para o Venturi 1 e 237 para o Venturi 2. Os valores $d$ estabelecidos de 0,9994 e 0,9999 para os Venturis 1 e 2, respectivamente, indicam uma dispersão quase nula dos dados da correlação, com respeito a reta 1:1.

A Figura 13 apresenta o erro na vazão calculada, expresso em porcentagem, em função da vazão observada e da velocidade na tubulação (a), e do sinal (b), para o Venturi 1(DN 50).

Os valores de variação percentuais extremos, para o Venturi 1, foram de $-6,03 \%$ para uma vazão de $8607 \mathrm{Lh}^{-1}$, velocidade na tubulação principal de $1,46 \mathrm{~m} \mathrm{~s}^{-1}$ e sinal de 7,70 e $6,71 \%$ para uma vazão de $6795 \mathrm{~L} \mathrm{~h}^{-1}$, velocidade de $1,31 \mathrm{~m} \mathrm{~s}^{-1}$ e sinal de 6,20 , sendo que $52,50 \%$ das vazões calculadas sobrestimaram as vazões observadas. A partir dos pontos extremos foi verificada uma diminuição do erro com o aumento da vazão e velocidade na tubulação.

Também foi determinada o erro percentual do Venturi 2 (DN 75); os valores máximos de variação foram $-6,30 \%$ para uma vazão $13457 \mathrm{Lh}^{-1}$, velocidade na tubulação principal de $1,01 \mathrm{~m} \mathrm{~s}^{-1}$ e sinal $8,60 \mathrm{e}, 6,13 \%$ correspondendo a uma vazão de $12878 \mathrm{~L} \mathrm{~h}^{-1}$, velocidade de $1,09 \mathrm{~m} \mathrm{~s}^{-1}$, sinal 10,10 , sendo que $56 \%$ das vazões calculadas estiveram acima da vazão real. A partir dos pontos citados verificou-se uma diminuição do erro com o aumento da velocidade na tubulação. 

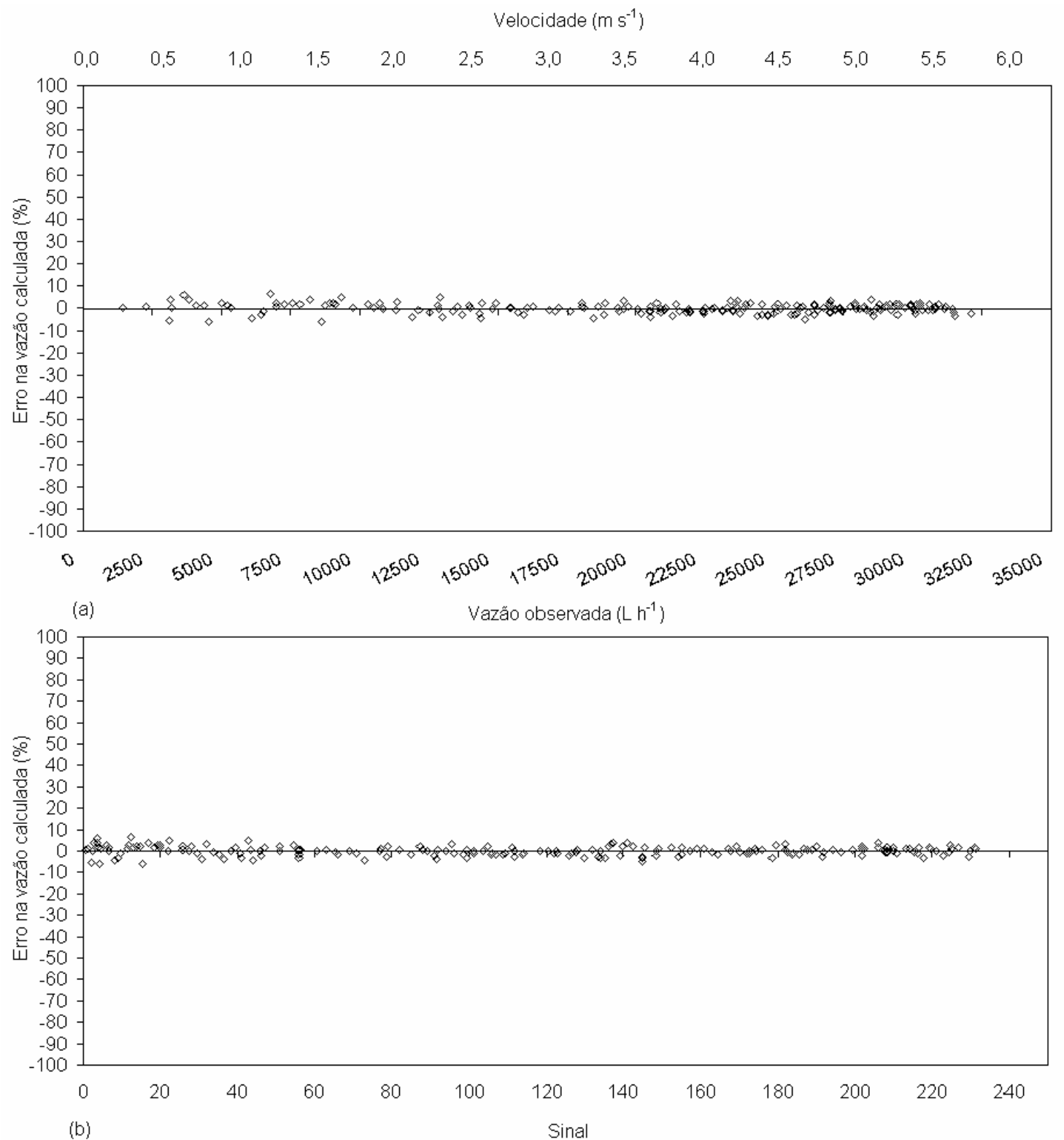

Figura 13 - Erro na vazão calculada em função da vazão observada e da velocidade na tubulação(a) e do sinal digital (b), para o Venturi 1 (DN 50)

A Figura 14 apresenta o erro percentual da vazão calculada em relação à vazão observada e à velocidade na tubulação principal (a) e do sinal (b) para o Venturi 2 (DN 75). 


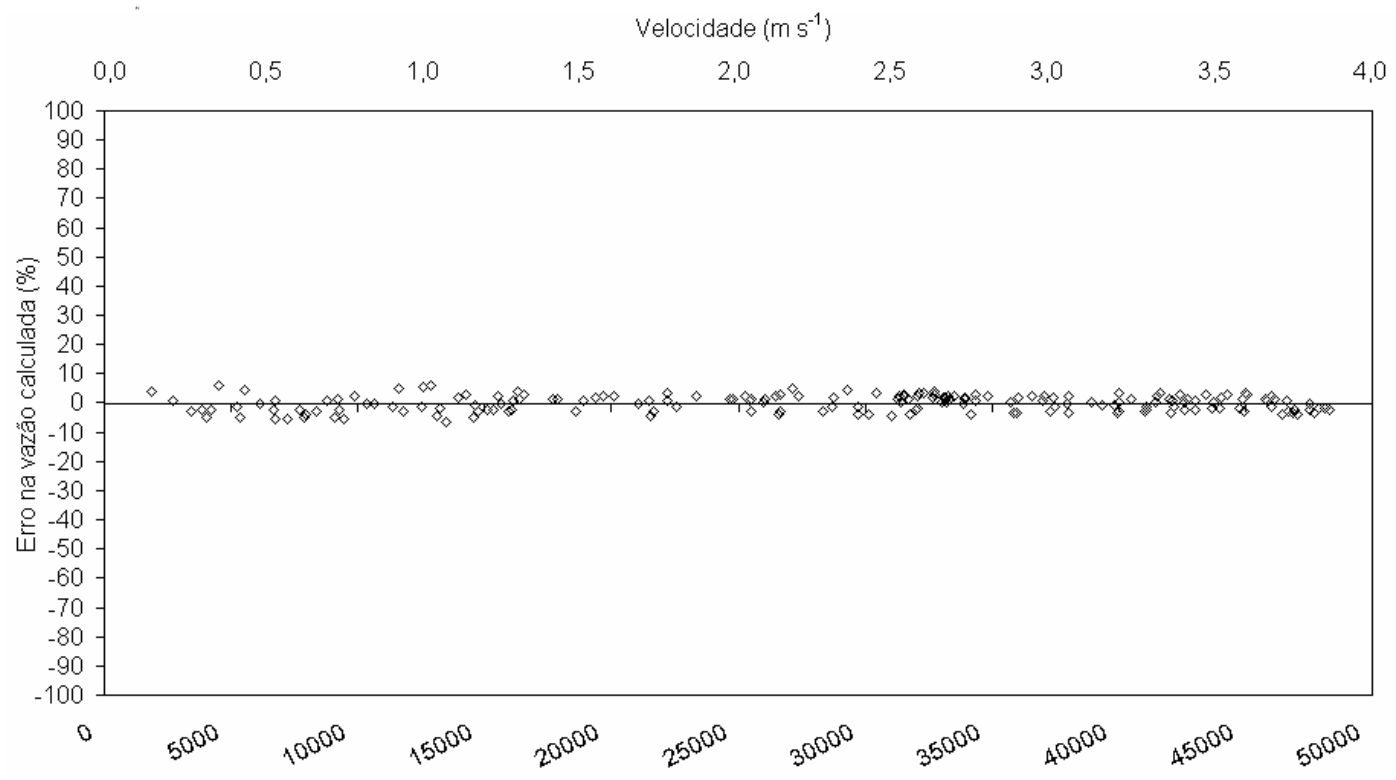

(a)

Vazão observada $\left(L h^{-1}\right)$

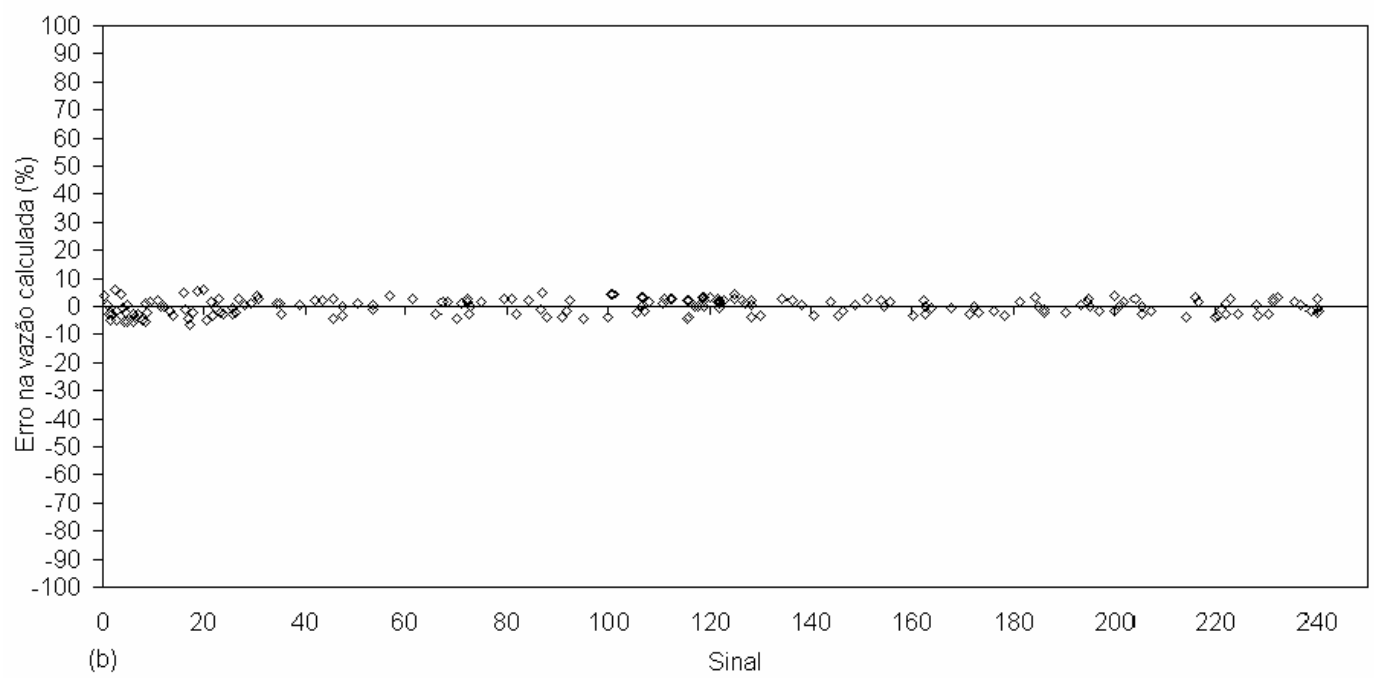

Figura 14 - Erro na vazão calculada em função da vazão observada e da velocidade na tubulação (a) e do sinal digital (b), para o Venturi 2 (DN 75) 


\subsection{Avaliação}

A partir das equações (17) e (18) foram desenvolvidos os programas para a medição da vazão, na linguagem "Tbasic", sendo os mesmos apresentados nos anexos B e C, para os Venturis 1 e 2, respectivamente.

Os dados fornecidos pelos Venturis foram comparados com a vazão medida pelo sistema GF SIGNET.

Para o medidor Venturi 1 (DN 50), a faixa de trabalho foi de 2329 até $32230 \mathrm{~L} \mathrm{~h}^{-1}$, com velocidades de $0,41 \mathrm{~m} \mathrm{~s}^{-1}$ a $5,95 \mathrm{~m} \mathrm{~s}^{-1}$ e número de Reynolds entre 18160 e 262000 , totalizando 200 leituras.

O medidor Venturi 2 (DN 75) foi avaliado para vazões na faixa de 2909 $\mathrm{L} \mathrm{h}^{-1}$ a $48259 \mathrm{~L} \mathrm{~h}^{-1}$, o que compreende velocidades de $0,23 \mathrm{~m} \mathrm{~s}^{-1}$ a 3,85 $\mathrm{m} \mathrm{s}^{-1}$, correspondendo a um número de Reynolds de 15295 a 253751, totalizando 220 leituras. Para os dois modelos, os valores citados correspondem aos fornecidos pelo medidor GF SIGNET, considerado como padrão.

A Figura 15 apresenta a dispersão de pontos relativos à correlação entre as vazões dos venturis e do GF SIGNET, em torno da reta 1:1. Assim como o coeficiente de determinação $\left(r^{2}\right)$ e o índice de concordância $(d)$.

Para o Venturi 1, houve uma correlação altamente significativa pelo teste "t" com um valor de 307. O índice de concordância de 0,9995 indica uma grande exatidão das medidas do Venturi em relação ao medidor padrão.

O Venturi 2 também apresentou uma correlação altamente significativa, com um valor "t" de 348. O valor do índice concordância de 0,9995 confirma a exatidão das medidas, como amostra a Figura 15 (b). 

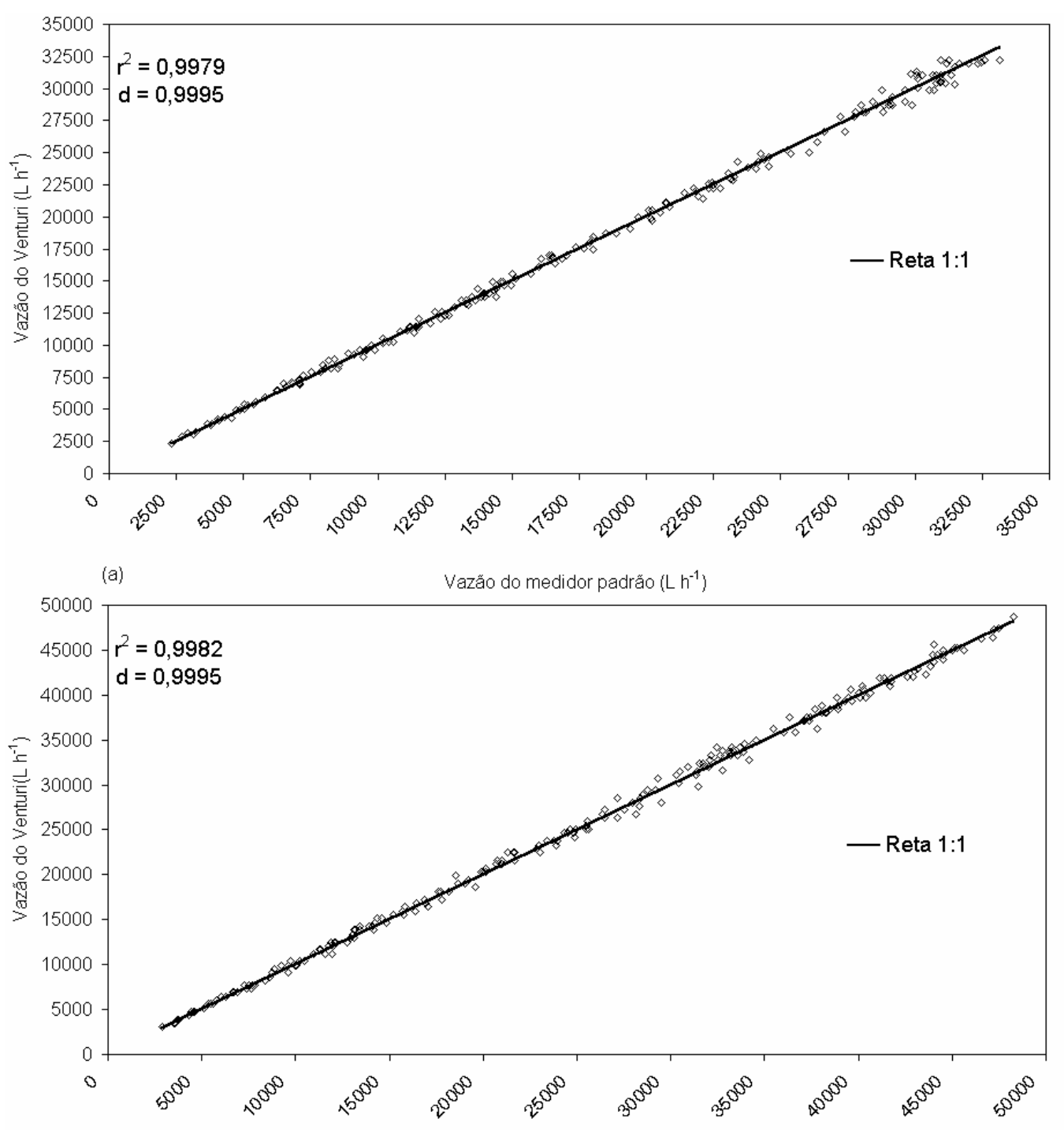

(b)

Vazăo do medidor padrão ( $\left(\mathrm{h}^{-1}\right)$

Figura 15 - Dispersão dos pontos representativos da correlação entre as vazões dos Venturis e o medidor padrão para o Venturi 1 (DN 50) (a) e Venturi 2 (DN 75) (b)

Na Figura 16, pode-se observar os desvios dos dados fornecidos pelos medidores Venturi, considerando vazão e velocidade na tubulação, medidas pelo medidor GF SIGNET.

O desvio da vazão do Venturi 1 (DN 50) apresentou valores entre $-5,73 \%$ e 7,44\%, para vazões de 4091 e $7032 \mathrm{Lh}^{-1}$. Com o aumento da vazão 
observaram-se menores desvios. Considerando a velocidade na tubulação, os pontos de maior variação correspondem 0,81 e 1,17 $\mathrm{m} \mathrm{s}^{-1}$, respectivamente. A vazão calculada pelo Venturi 1 , apresentou valores superiores aos calculado pelo GF SIGNET em $69,6 \%$ das medições, sendo que $69 \%$ das leituras tiveram um desvio inferior à $\pm 2,5 \%$.

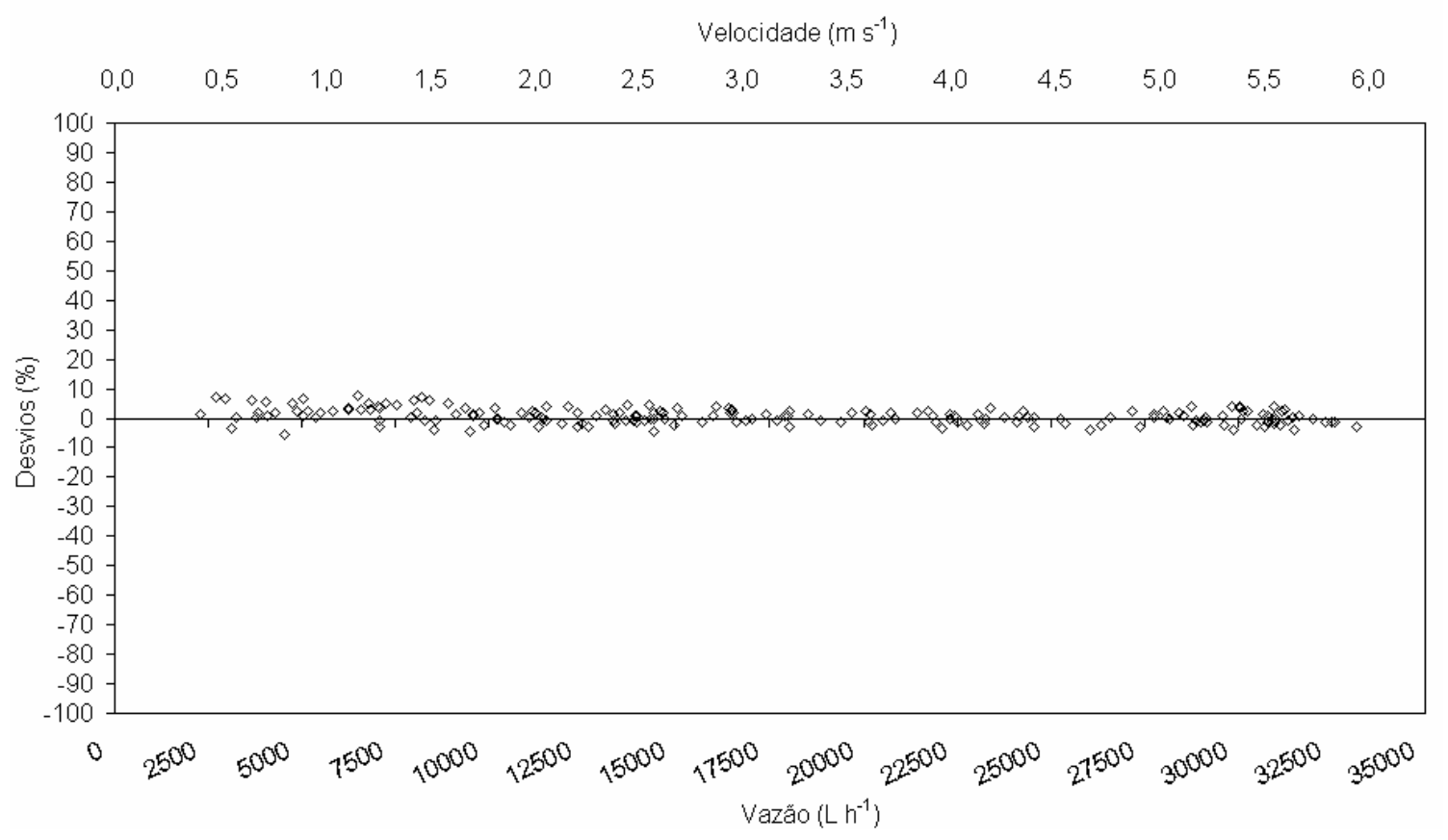

Figura 16 - Desvios dos dados de vazão fornecidos pelo Venturi, em função da velocidade e da vazão medida pelo GF SIGNET, para o Venturi 1 (DN 50)

A Figura 17 apresenta a variação dos desvios dos valores fornecidos pelo Venturi 2 (DN 75).

Os desvios da vazão estimada pelo Venturi 2 (DN 75), variou percentualmente entre $-6,20 \%$ e $7,17 \%$, correspondendo a vazões de 11232 $\mathrm{Lh}^{-1}$ e $9936 \mathrm{Lh}^{-1}$, respectivamente; para vazões superiores os desvios diminuíram. Os pontos de maior variação correspondem a velocidades de 0,95 
e $0,74 \mathrm{~m} \mathrm{~s}^{-1}$, sendo que $64,55 \%$ das leituras tiveram os desvios contidos na faixa de $\pm 2,5 \%$.

A faixa de trabalho do Venturi 2 (DN 75) poderia ter sido aumentada com a utilização de um sensor de pressão de maior amplitude de medição, porém, com perda de precisão nas leituras.

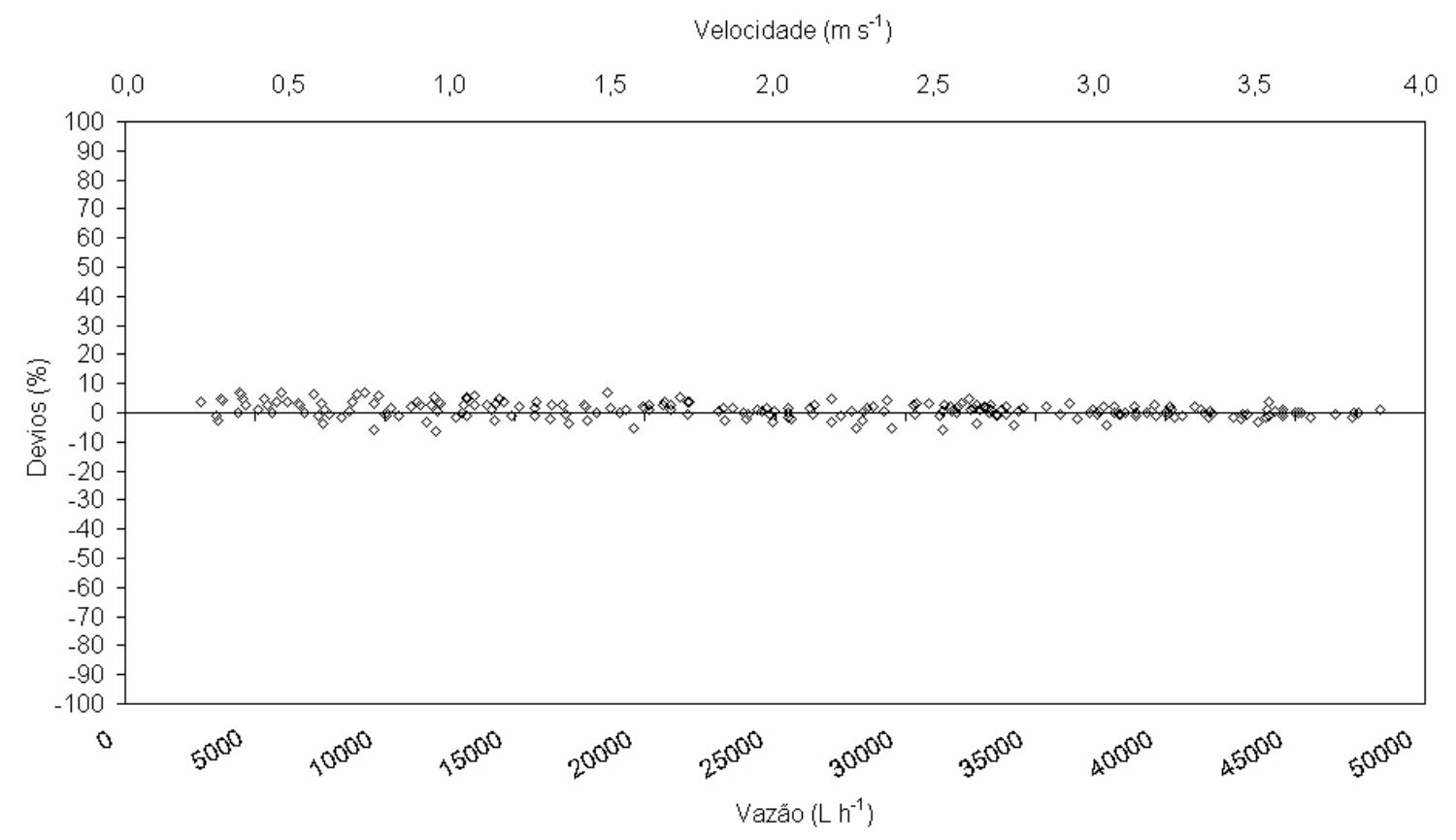

Figura 17 - Desvios dos dados de vazão fornecidos pelo Venturi, em função da velocidade e da vazão medida pelo GF SIGNET, para o Venturi 2 (DN 75)

Para os dois modelos os desvios de mais de $50 \%$ das leituras foi inferior $\mathrm{a} \pm 2,5 \%$.

Considerando que uma aplicação potencial dos medidores Venturi seria a medição de vazões em sistemas de irrigação, a faixa de trabalho em que os mesmos foram testados está de acordo com a velocidade recomendada por Bernardo (1995) para dimensionamento econômico de tubulações de recalque, que varia de 0,60 a 2,40 $\mathrm{m} \mathrm{s}^{-1}$. Para tubulações de recalque de sistemas elevatórios Porto (1999) recomenda velocidades de 0,60 a $3 \mathrm{~m} \mathrm{~s}^{-1}$, sendo as 
mais usuais de 1,50 a $2 \mathrm{~m} \mathrm{~s}^{-1}$. Os dois medidores testados apresentaram maiores desvios na faixa de velocidade até $1,5 \mathrm{~m} \mathrm{~s}^{-1}$, sendo que a maior precisão dos Venturis foi na faixa de velocidade de 3 a $5 \mathrm{~m} \mathrm{~s}^{-1}$. A Tabela 4 apresenta o desvio médio por faixa de velocidade, para os dois Venturis testados.

Tabela 4. Desvio percentual médio nas leituras dos Venturis testados por faixa de velocidade

\begin{tabular}{ccccc}
\hline Modelo & \multicolumn{4}{c}{ Velocidade na tubulação $\left(\mathrm{m} \mathrm{s}^{-1}\right)$} \\
& até 1,5 & de 1,5 a 3 & de 3 a 5 & $>5$ \\
\hline Venturi 1 & de $-2,36$ & de $-1,60$ & de $-1,53$ & de $-1,61$ \\
& a 3,43 & a 2,28 & a 1,35 & a 1,97 \\
Venturi 2 & de $-2,01$ & de $-1,95$ & de 1 & \\
& a 3,37 & a 1,85 & a 1,29 & - \\
\hline
\end{tabular}
$\mathrm{m} \mathrm{s}^{-1}$

Em geral, os Venturis apresentaram menor precisão que a prevista na literatura: a mesma deveria estar em torno de \pm 1 a $\pm 1,50 \%$ segundo Bringer (2003). Para Delmée (1982) a precisão do Venturi clássico usinado varia de $\pm 0,75$ a $\pm 1,70 \%$.

Os Venturis tiveram uma tendência a sobrestimar a vazão. Este fato possivelmente pode ter sido originado na programação, pois o Basic Step 1 realiza operações matemáticas básicas, não tendo um comando específico para a raiz quadrada. Assim, para se realizar essa operação, utilizou-se um comando lógico no programa que procura um número que elevado ao quadrado seja maior ou igual ao sinal. 


\subsection{Coeficiente de descarga}

Os coeficientes de descarga para os dois modelos, foram determinados a partir da razão entre as equações de vazão real e teórica, ou seja, equações (17) e (14) para o Venturi 1 (DN 50) e equações (18) e (15) para o Venturi 2 (DN 75).

Os valores, de coeficiente de descarga, estabelecidos foram de 0,967 para o Venturi 1 e 0,932 para o Venturi 2 (DN 75). Em ambos casos os valores foram menores do que os citados na bibliografia, conforme comentado na revisão de literatura.

\subsection{Perda de carga}

Para determinar a perda de carga dos Venturis, foi utilizado um manômetro diferencial de mercúrio, sendo que os valores observados incluem a perda de carga localizada dos acessórios utilizados para conectar os Venturis na linha. Os dados de vazão foram calculados pelo programa desenvolvido previamente. A perda de carga teórica foi determinada por dois métodos: o proposto por Porto (1999), e o proposto por Azevedo Netto et al. (1998). A Figura 18 apresenta a perda de carga teórica e a perda de carga observada em função da vazão.

A análise visual da Figura 18 (a), mostra que a perda de carga observada do Venturi 1 (DN 50), foi maior do que a teórica calculada pelo método de Porto, porém inferior aos valores calculados pelo método de Azevedo, sendo os valores observados mais próximos ao segundo método teórico.

A perda de carga observada no Venturi 2 (DN 75), também apresentou valores intermediários em relação às perdas de carga calculadas teoricamente. Entretanto, neste caso, os valores calculados utilizando a equação proposta por Azevedo apresentaram-se mais baixos como amostra a Figura 18(b). 
Deve-se observar que os valores de $\mathrm{K}_{\mathrm{hf}}$ utilizados para determinar a perda de carga teórica foram obtidos de varias fontes, não representando exatamente as peças avaliadas, tendo os Venturis condições próprias de acabamento interno, montagem, etc.
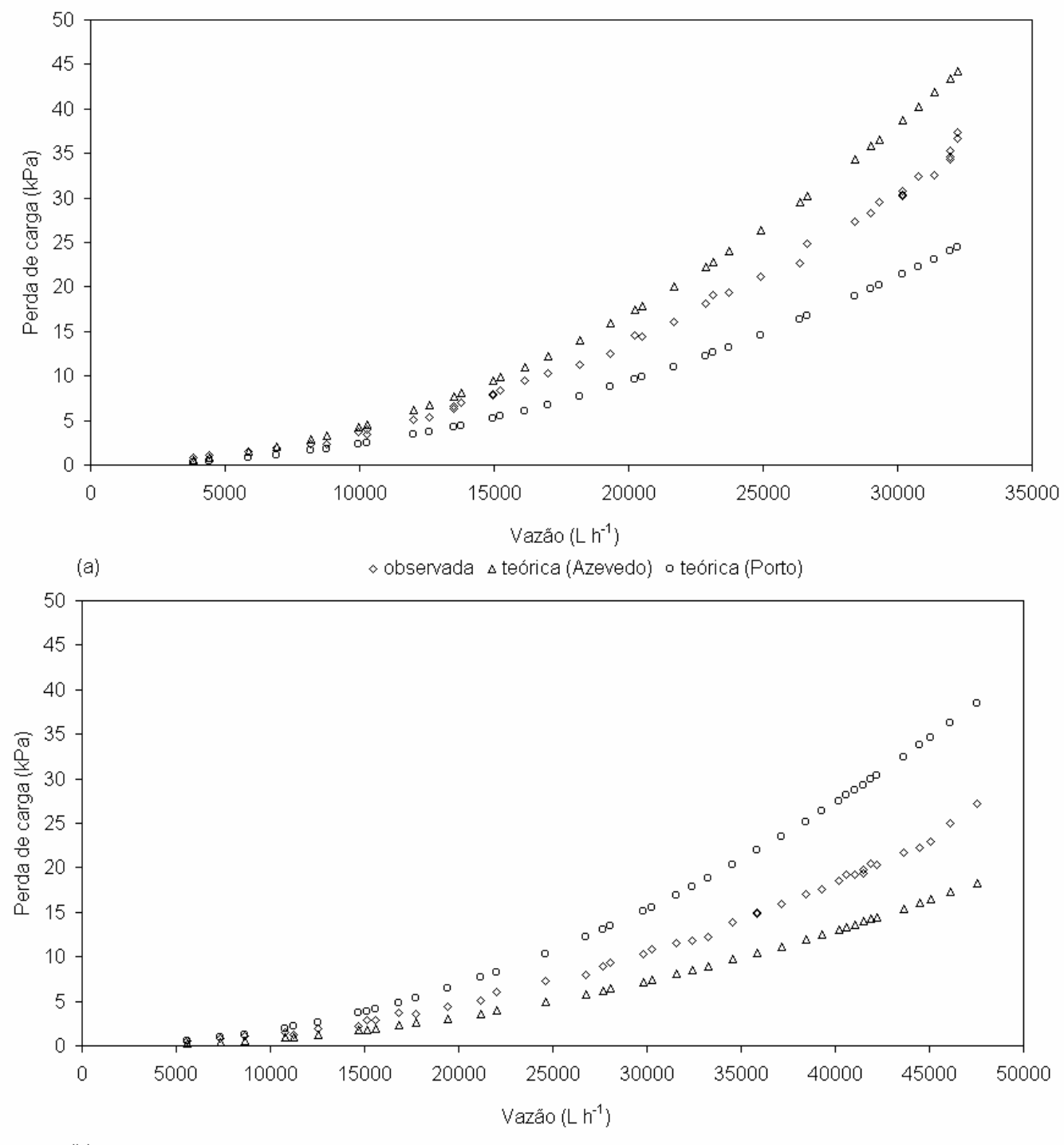

(b)

\& observada $\Delta$ teórica (Azevedo) o teórica (Porto)

Figura 18 - Perda de carga observada e perda de carga teórica calculada segundo as expressões propostas por 2 autores, em função da vazão, para o Venturi 1 (a) e Venturi 2(b) 
Também foram estabelecidas equações do tipo potencial para determinar a perda de carga nos Venturis a partir da vazão. A Tabela 5 apresenta as equações de perda de carga em função da vazão dos Venturis.

Tabela 5. Equações de perda de carga dos Venturis $(\mathrm{kPa})$ testados em função da vazão $\left(L h^{-1}\right)$

\begin{tabular}{ccc}
\hline Modelo & Equação & $\mathrm{r}^{2}$ \\
\hline Venturi 1 & $\mathrm{hf}=1.10^{-7} \mathrm{Q}^{1.8607}$ & 0,9934 \\
Venturi 2 & $\mathrm{hf}=3.10^{-8} \mathrm{Q}^{1,9017}$ & 0,9947 \\
\hline
\end{tabular}

\subsection{Lista de materiais e relação de preços}

A seguir apresenta-se uma relação dos materiais usados na construção dos Venturis, separando as partes estrutural e eletrônica.

A cotação dos componentes estruturais (tubulação e fibra de vidro) foi feita em estabelecimentos comerciais de Piracicaba e região, e os componentes eletrônicos, foram cotados através da Internet.

O custo total dos materiais utilizados para a construção do Venturi 1 (DN 50) foi de $R \$ 220,32$, sendo que os componentes eletrônicos representaram um $65,36 \%$, ou seja, $R \$ 144,00$. Outro componente importante dentro do custo total foi o tarugo de PVC utilizado para a construção do molde; seu custo foi de R\$ 47,60 , correspondendo a $21,6 \%$ do total.

Para a construção do Venturi 2 (DN 75), gastou-se $R \$ 242,36$, sendo que os componentes eletrônicos constituíram $59,41 \%$ do total, ou seja, $R \$ 144,00$. $\mathrm{O}$ custo da parte eletrônica foi o mesmo para os dois modelos de Venturis. $\mathrm{O}$ custo do material para o molde (PVC), foi de $\mathrm{R} \$ 61,60$, representando $25,4 \%$ do total, sendo que este componente pode ser reutilizável na fabricação de outros Venturis. Considerando-se uma cotação de 2,98 R $\$ / U S \$$, ressaltando-se que os custos dos componentes eletrônicos podem variar em função do frete. 
Para ambos medidores o custo total dos materiais representa menos de $10 \%$ de alguns medidores de vazão disponíveis no mercado.

Na Tabela 6 pode-se observar a lista de materiais, assim como o custo unitário e total dos componentes eletrônicos.

Tabela 6. Lista de materiais e custos da parte eletrônica dos Venturis construídos

\begin{tabular}{ccccc}
\hline Quantidade & Especificação & Unidade & $\begin{array}{c}\text { Custo } \\
\text { Unitário }(\mathrm{R} \$)\end{array}$ & $\begin{array}{c}\text { Total } \\
(\mathrm{R} \$)\end{array}$ \\
\hline 1,00 & Microcontrolador & Unid & 65,00 & 65,00 \\
1,00 & Display LCD Serial & Unid & 40,00 & 40,00 \\
1,00 & Placa fenolite & Unid & 2,00 & 2,00 \\
1,00 & Transdutor de pressão & Unid & 30,00 & 30,00 \\
1,00 & Regulador de tensão & Unid & 3,00 & 3,00 \\
1,00 & Conversor AD & Unid & 4,00 & 4,00 \\
\hline
\end{tabular}

Nota: os dois Venturis construídos utilizaram os mesmos componentes

As Tabelas 7 e 8 apresentam a lista de materiais, assim como o custo unitário e total dos componentes estruturais dos Venturis 1 e 2, respectivamente. 
Tabela 7. Lista de materiais e custos da parte estrutural do Venturi 1 (DN 50)

\begin{tabular}{|c|c|c|c|c|}
\hline Quantidade & Especificação & Unidade & $\begin{array}{c}\text { Custo } \\
\text { Unitário (R\$) }\end{array}$ & $\begin{array}{l}\text { Total } \\
(\mathrm{R} \$)\end{array}$ \\
\hline 0,01 & Acelerador de cobalto 6\% & Litros & 30,00 & 0,30 \\
\hline 1,00 & Rolete $14 \times 20 \mathrm{~mm}$ & Unid & 7,00 & 7,00 \\
\hline 0,23 & Resina & $\mathrm{kg}$ & 7,70 & 1,77 \\
\hline 0,01 & Desmoldante & Litros & 2,85 & 0,03 \\
\hline 0,01 & Centerox & $\mathrm{kg}$ & 14,00 & 0,14 \\
\hline 0,01 & Cera desmoldante & $\mathrm{kg}$ & 6,00 & 0,06 \\
\hline 0,07 & Gel & $\mathrm{kg}$ & 8,10 & 0,57 \\
\hline 1,00 & Solvente limpeza & Litros & 3,00 & 3,00 \\
\hline 2,00 & Pincel & Unid & 2,90 & 5,80 \\
\hline 0,05 & Manta de fibra de vidro & $\mathrm{m}^{2}$ & 12,00 & 0,60 \\
\hline 2,00 & Adaptador solda rosca $50 \times 1$ 1/2 & Unid & 3,50 & 7,00 \\
\hline 0,05 & Tubo soldável 32 mm & $\mathrm{m}$ & 1,50 & 0,07 \\
\hline 0,49 & Tubo soldável 50 mm & $\mathrm{m}$ & 5,00 & 2,42 \\
\hline 1,70 & Tarugo PVC 50 mm & $\mathrm{kg}$ & 28,00 & 47,60 \\
\hline
\end{tabular}


Tabela 8. Lista de materiais e custos da parte estrutural do Venturi 2 (DN 75)

\begin{tabular}{ccccc}
\hline Quantidade & Especificação & Unidade & $\begin{array}{c}\text { Custo } \\
\text { Unitário }\end{array}$ & $\begin{array}{c}\text { Total } \\
(\mathrm{R} \$)\end{array}$ \\
& & & $(\mathrm{R} \$)$ & \\
\hline 0,01 & Acelerador de cobalto 6\% & Litros & 30,00 & 0,30 \\
1,00 & Rolete $14 \times 20 \mathrm{~mm}$ & Unid & 7,00 & 7,00 \\
0,60 & Resina I & $\mathrm{kg}$ & 7,70 & 4,62 \\
0,01 & Desmoldante & Litros & 2,85 & 0,03 \\
0,02 & Centerox & $\mathrm{kg}$ & 14,00 & 0,28 \\
0,01 & Cera desmoldante & $\mathrm{kg}$ & 6,00 & 0,06 \\
0,15 & Gel & $\mathrm{kg}$ & 8,10 & 1,22 \\
1,00 & Solvente limpeza & Litros & 3,00 & 3,00 \\
2,00 & Pincel & Unid & 2,90 & 5,80 \\
0,12 & Manta de fibra de vidro & $\mathrm{m}^{2}$ & 12,00 & 1,44 \\
2,00 & Adaptador solda rosca $75 \times 2$ 1/2 & Unid & 4,50 & 9,00 \\
0,04 & Tubo soldável $40 \mathrm{~mm}$ & $\mathrm{~m}$ & 3,00 & 0,11 \\
0,60 & Tubo soldável $75 \mathrm{~mm}$ & $\mathrm{~m}$ & 7,00 & 4,20 \\
2,20 & Tarugo PVC $70 \mathrm{~mm}$ & $\mathrm{~kg}$ & 28,00 & 61,60 \\
\hline
\end{tabular}




\section{CONCLUSÕES}

Com base nos resultados obtidos e considerando-se as condições em que foram realizados os testes de laboratório, chegou-se às seguintes conclusões:

a) A construção artesanal de medidores de vazão Venturi é viável tecnicamente e apresenta custo relativamente baixo;

b) A avaliação demonstrou que os Venturis construídos, após calibração, forneceram medidas com boa precisão e exatidão quando comparadas com o medidor utilizado como padrão;

c) A faixa de trabalho dos Venturis construídos e avaliados está de acordo com as velocidades usuais recomendadas para as tubulações de recalque de sistemas de irrigação;

d) Para ambos os Venturis testados os desvios nas leituras foram maiores para velocidades inferiores a $1,5 \mathrm{~m} \cdot \mathrm{s}^{-1}$, observando-se menores desvios para velocidades maiores. 
ANEXOS 
ANEXO A - Programa em linguagem "Tbasic" para leitura do AD

Symbol CS $=7$

Symbol CLK $=5$

Symbol DO = 6

Symbol DOpin $=$ pin6

Symbol LCD $=4$

Symbol ADbits $=b 1$

Symbol AD = w1

Symbol $w=w 2$

Symbol ssinal $=\mathrm{w} 3$

Symbol resultado $=\mathrm{w} 4$

Symbol $\mathrm{cmd}=254$

Symbol clear $=1$

Symbol home $=2$

High CS

Again:

gosub lerAD

gosub media

gosub display

goto Again 'Termina o looping

- Rotina para a leitura

lerAD:

low CLK

low CS

pulsout CLK, 1

input DO

let $A D=0$ for Adbits $=1$ to 8

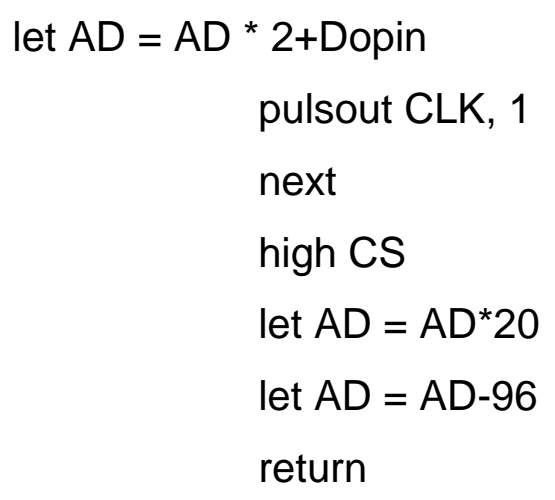

media:

ssinal $=0$

For $w=1$ to 25 step 1

Gosub lerAD

Ssinal $=$ ssinal $+A D$

Next

let ssinal $=\operatorname{ssinal} / 25$

Return

' Rotina display

display:

serout 4,n2400,(cmd,home)

serout 4,N2400,(\#ssinal)

pause 250

return 
ANEXO B - Programa para disponibilizar leituras de vazão utilizando o Venturi 1 Symbol CS $=7$ for Adbits $=1$ to 8

Symbol CLK $=5$

let $A D=A D * 2+D O p i n$

Symbol DO = 6

pulsout CLK, 1

Symbol DOpin $=$ pin6

next

Symbol LCD $=4$

high CS

Symbol ADbits = b1

let $A D=A D * 2$

Symbol AD = w1 ${ }^{\prime}$

return

Symbol $w=w 2$

media:

Symbol ssinal $=w 3$

$A D=0$

Symbol i $=\mathrm{w} 4$

ssinal $=0$

Symbol data $=w 5$

For $w=1$ to 100 step 1

Symbol cmd $=254$

Gosub lerAD

Symbol clear $=1$ $s \sin a l=s \sin a l+A D$

Symbol home $=2$

Next

let ssinal $=$ ssinal

High CS

return

Again:

gosub lerAD

gosub media

gosub aux

gosub display

goto Again

lerAD:

low CLK

low CS

pulsout CLK, 1

input DO

let $A D=0$ aux:

aux0:

If ssinal <= 980 then vazao0

Let ssinal=ssinal

Aux1:

If ssinal $>980$ then vazao 1

Let ssinal=ssinal

vazao0:

let ssinal $=0$

return

vazao1: 
Let ssinal $=$ ssinal -980

For $\mathrm{i}=0$ to 160

let data $=i \star i$

IF data $>=$ ssinal THEN

transformacao

let data $=\mathrm{i}$

next

Transformacao:

Let ssinal=i

Let ssinal $=\mathrm{ssinal} / 10$

let ssinal $=2069 *$ ssinal

return

display:

serout 4,n2400,(cmd,home)

serout 4,N2400,(\#ssinal, " LPH ")

pause 250

return 
ANEXO C - Programa para disponibilizar leituras de vazão utilizando o Venturi 2

Symbol CS $=7$

Symbol CLK = 5 '

Symbol DO $=6$

Symbol DOpin $=$ pin6

Symbol LCD $=4$

Symbol ADbits $=b 1^{\prime}$

Symbol $A D=w 1{ }^{\prime}$

Symbol $w=w 2$

Symbol ssinal $=$

Symbol i $=$ w4

Symbol data $=w 5$

Symbol cmd $=254$

Symbol home $=2$

high CS

Again:

gosub lerAD

gosub media

gosub aux

gosub display

goto Again 'Termina o looping

lerAD:

low CLK

low CS

pulsout CLK, 1

input DO

let $A D=0$

for ADbits $=1$ to 8 let $A D=A D$ * 2+Dopin

pulsout CLK, 1

next

high CS

let $A D=A D * 2$

return

media:

$A D=0$

ssinal $=0$

For $w=1$ to 100 step 1

Gosub lerAD

ssinal $=$ ssinal $+A D$

Next

let ssinal $=$ ssinal

return

aux:

aux0:

If ssinal <= 980 then vazao0

let ssinal=ssinal

aux1:

If ssinal $>980$ then vazao1

let ssinal=ssinal

vazao0:

let ssinal $=0$

return

vazao1:

let ssinal $=$ ssinal -980

For $\mathrm{i}=0$ to 160 
let data $=i * i$

$$
\text { IF data }>=\text { ssinal THEN }
$$

transformacao

$$
\begin{aligned}
& \text { let data }=\mathrm{i} \\
& \text { next } \\
& \text { Transformacao: } \\
& \text { Let ssinal=i } \\
& \text { Let ssinal=ssinal/10 } \\
& \text { let ssinal = 3052*ssinal } \\
& \text { return }
\end{aligned}
$$

display:

serout 4,n2400,(cmd,home)

serout 4,N2400,(\#ssinal, " LPH ")

pause 250

return 


\section{REFERÊNCIAS BIBLIOGRÁFICAS}

AGUILA, H. Medición de flujo.

http://www.ramos.utfsm.cl/pqui/cpi/contenidos/apuntes/CAPITULO_33.pdf (08 out. 2003)

ANGNES, D.L. Introdução ao microcontrolador Basic Step. http://www.tato.ind.br/files/Microcontroladores\%20BASIC\%20Step1.pdf set. 2003)

AZEVEDO NETTO, J.M.; FERNANDEZ y FERNANDEZ, M.; ARAUJO, R.; EIJI ITO, A. Manual de hidráulica. 8.ed. São Paulo: Blucher, 1998. 669 p.

BAUM, M.C.; DUKES, M.D.; HAMAN, D.Z. Selection and use of water meters for irrigation water measurement. http://edis.ifas.ufl.edu/BODY_AE106 (09 out. 2003)

BERNARDO, S. Manual de irrigação. 6.ed. Viçosa: UFV, 1995, 657 p.

BRINGER. Elementos primários de vazão.

http://www.bringer.com.br/download / brfe's-3.pdf (17 set. 2003) 
CARRION, P.; SANCHEZ, C.; ORTEGA, J.F.; CALVO, M.A.; MONTERO, J.; TARJUELO, J.M. Automatización del bombeo en una instalación de riego por goteo. http://www.us.es/ciberico/2carrion.pdf (9 out. 2003)

CARVAlHo, D. F. de; SILVA, W. A. da; MÉdiCE; L. O. PEREIRA, M. G. Avaliação de um sistema automático de baixo custo para manejo da irrigação (compact disc). In: CONGRESSO BRASILEIRO DE ENGENHARIA AGRÍCOLA, 30., Foz de Iguaçu, 2001. Foz do Iguaçu: CONBEA, 2001.

CONTRERAS, M.A.; SALGADO, G.A.; SANCHEZ, M.A. Medición y control de caudal para la implementación de un sistema distribuido. http://proton.ucting.udg.mx/expodec/julio2001/proyectos/pdf/lce19.PDF out. 2003)

DE PACO, J.L. Fundamentos del calculo hidráulico en los sistemas de riego y drenaje. Madrid: IRYDA, 1993. 398 p.

DELMÉE, G.J. Manual de medição de vazão. 2.ed. São Paulo: Edgard Blücher, 1982. $476 \mathrm{p}$.

DENÍCULI, W. Medidores de vazão tipo orifício. Viçosa: UFV, 1990.43 p.

ESTADOS UNIDOS. Department of the Interior. Bureau of Reclamation. Water measurement manual.

http://www.usbr.gov/pmts/hydraulics_lab/pubs/wmm/index.htm (09 out. 2003)

FEITOSA FILHO, J.C. Otimização hidráulica e manejo de injetores tipo venturi duplo para fins de quimigação. Piracicaba, 1998. 164 p. Tese (Doutorado) Escola Superior de Agricultura "Luiz de Queiroz", Universidade de São Paulo. 
GALLI, M.; ONOFRE, R.M. Medição de vazão.

http://www.professorelmo.pop.com.br/vazao.pdf (17 set. 2003)

GF SIGNET. +GF+ SIGNET 2536/3-8512-XX Sensor para baixas vazões. http://www.gfsignet.com/products/pdf/2536por.pdf (10 out 2003)

GF SIGNET. Instruções do transmissor de vazão 8550-1 +GF+ SIGNET. http://www.gfsignet.com/products/pdf/8550-2por.pdf (10 out 2003)

GUTIÉRREZ, L.G. Teoría de la medición de caudales y volúmenes de agua e instrumental necesario disponible en el mercado.

http://www.igme.es/internet/web_aguas/igme/publica/pdfart2/teoria.pdf (18 set. 2003)

HILL, R. How good is your water measurement. http://extension.usu.edu/files/engrpubs/biewm01.pdf (10 out. 2003)

HYPERPHYSICS. Venturi flowmeter. http://hyperphysics.phyastr.gsu.edu/hbase/fluids/venturi.html. (16 set. 2003)

LEE, J. Open channel flow measurement.

http://water.wku.edu/wastewater/readingroom/OpenChannelFlowMeasureme nt.pdf (10 out. 2003)

LEOPOLDO, P.R.; SOUSA, A. P. Hidrometria: medição de vazão. Botucatu: UNESP, 1979. 71p.

LOPEZ, J.R.; ABREU, J.M.H.; REGALADO, A.P.; HERNÁNDEZ, J.F. Riego localizado. Madrid: IRYDA, 1992. 405 p. 
LOSADA, A. El riego fundamentos hidráulicos. Madrid: Mundi-Prensa, 1988. $431 \mathrm{p}$.

MARTINEZ, C.B.; AGUIRRE, L.A. Sistema automático para medição de rendimento de grupos hidro-geradores aplicado a pequenas centrais hidrelétricas. http://www.xviisnptee.com.br/acervo_tecnico/memoria/ xvi/01_Grupo_I_Ggh/GGH-003.pdf (21 set. 2003)

MOTOROLA. Integrated silicon pressure sensor, on-chip signal conditioned, temperature compensated and calibrated. http://http://e-www.motorola.com/files/sensors/doc/data_sheet/MPX5100.pdf (04 set. 2003)

MUNDO, M.; CARRILLO, M.; MARTINEZ, P. Calibración en laboratorio de un medidor totalizador volumetrico para pozos de riego (compact disc). In: CONGRESSO NACIONAL DE RIEGOS, 29., Zaragoza, 2001. Zaragoza: Sociedad Nacional de riego, 2001.

\section{NATIONAL SEMICONDUCTOR CO. ADC0831/ADC0832/ADC0834/ADC0838} 8-bit serial I/O A/D converters with multiplexer options. http://cache.national.com/ds/AD/ADC0831.pdf (04 set. 2003)

OLALLA, J.R: Instrumentación para las telecomunicaciones sensores de flujo: El tubo venturi.

http://www.ele.uva.es/ lourdes/docencia/it//Trabajos03/Sensores\%20de\%20fl ujo\%20-\%20tubo\%20venturi.pdf (11 out. 2003)

PASAYE, J.J.R. Introducción a los microcontroladores. http://lie.fie.umich.mx/downloads/control/intro-microcon.pdf (09 out. 2003) 
PEZZIN, M.Z. Curso de automação.

http://www.uri.com.br/ mzp/cursos/Automacao/sensores.htm\#6 (10 out. 2003)

PINTO, O.E.; CHERBAKIAN, E.H.; INOUE M.M.; DA SILVA, G.F. Automação de estação de tratamento de água (compact disc). In: CONGRESSO BRASILEIRO DE ENGENHARIA SANITÁRIA E AMBIENTAL, 19., Foz de Iguaçu, 1997. Foz de Iguaçu: ABES, 1997. 4 p.

PIZARRO, F.C. Riegos localizados de alta frecuencia (RLAF), goteo, microaspersión, exudación. 3.ed. Madrid: Mundi-Prensa, 1996. 513 p.

PORTO, R.M. Hidráulica básica. 2.ed. São Carlos: USP, 1999, 540 p.

PROGRAMA NACIONAL DE COMBATE AO DESPERDICIO DE AGUA. Macromedição: versão preliminar.

http://www.geocities.com/hidrometro/pncda_macro.pdf (06 jun. 2003)

ROGERS, D.H., BLACK, R.D. Irrigation water measurement. http://www.oznet.ksu.edu/library/ageng2/l877.pdf (8 out. 2003)

ROGERS, D.H., CLARK, G.; ALAM, M. Irrigation water measurement as a management tool. http://www.oznet.ksu.edu/library/ageng2/l878.pdf (09 out. 2003)

SCHNEIDER, P. Medição de pressão e vazão em fluidos.

http://www.geste.mecanica.ufrgs.br/pss/medterm/Pressao_vazao.pdf (19 set. 2003) 
SOUZA, R.O.R.M. Desenvolvimento e avaliação de um sistema de irrigação automatizado para áreas experimentais. Piracicaba, 2001. 70 p. Dissertação (Mestrado) - Escola Superior de Agricultura "Luiz de Queiroz", Universidade de São Paulo.

SPINK, L.K. Principles and practice of flow meter engineering. 9. ed. Foxboro: The Foxboro Company, 1967. 575 p.

TESLA. Caudal.

http://tesla.cuao.edu.co/automatica/jcmena/Variables/CAUDAL.pdf (21 set. 2003)

TESTEZLAF, R.; MATSURA, E.E. Automação aplicada a fertilização. In: FOLEGATTI, M.V. (Coord.). Fertirrigação: citrus, flores, hortaliças. FOLEGATTI, M. V. Coord. Guaíba: Agropecuária, 1999. 460p.

ULLMANN, M.N.; SOCCOL, O.J.; ARAUJO, J.C.de. Analise comparativa de medidores diferenciais de vazão tipo orifício padrão concêntrico, bocal padrão de fluxo e tubo venturi. In: CONGRESSO BRASILEIRO DE ENGENHARIA AGRícolA, 27., Poços de Caldas, 1998. Anais. Poços de Caldas: CONBEA, 1998. p.115-117.

VILELA, L.A.A.; BOTREL, T.A.; SOCCOL, O.J.; GERVÁSIO, E.S.; RETTORE NETO, O. Dispositivo para monitoramento da operação de conjuntos motobomba elétricos. Engenharia Agrícola, v.23, n.2, p.250-256, 2003.

VILELA, L. A.A.; CARVALHO, H. P.; PRADO, G.; BOTREL, T.A. Construção e calibração de um manômetro digital microprocessado (compact disc). In: CONGRESSO BRASILEIRO DE ENGENHARIA AGRÍCOLA, 32., Goiânia, 2003. Goiânia: CONBEA, 2003. 4p. 
ZARATE, R.N. Desenvolvimento e avaliação de dois injetores de fertilizantes tipo venturi. Piracicaba, 1995. 67 p. Dissertação (Mestrado) - Escola Superior de Agricultura "Luiz de Queiroz", Universidade de São Paulo.

ZARATE, R.N.; BOTREL, T. A. Desenvolvimento de dois injetores de fertilizante tipo venturi. In: WORKSHOP FERTIRRIGAÇÃO, 2., Piracicaba, 2001. Piracicaba: ESALQ, Departamento de Engenharia Rural, 2001. p.112-123. 